\title{
Circadian rhythms of sexual activities in moths: a review
}

\author{
Astrid T. Groot ${ }^{1,2 *}$ \\ ${ }^{1}$ Department of Evolutionary Biology, Institute for Biodiversity and Ecosystem Dynamics, University of Amsterdam, Amsterdam, Netherlands \\ ${ }^{2}$ Department of Entomology, Max Planck Institute for Chemical Ecology, Jena, Germany
}

\section{Edited by:}

Emmanuelle Jacquin-Joly, Institut

National de la Recherche

Agronomique, France

Reviewed by:

Monika Stengl, Universität Kassel, Germany

Christine Merlin, Texas A\&M

University, USA

*Correspondence:

Astrid T. Groot, Department of Evolutionary Biology, Institute for Biodiversity and Ecosystem

Dynamics, University of

Amsterdam, Science Park 904,

1098 XH Amsterdam, Netherlands e-mail: a.t.groot@uva.nl
The circadian rhythm of behavior has interested many researchers in the past decades, yet amazingly little is known on the evolution of natural variation in circadian rhythms of behavior. Most research has been focused on identifying the circadian clock genes that form an intricate clock network, which turns out to be more complex with every discovery. To understand the importance of circadian rhythms of behavior in speciation, genetic analyses should be conducted on intra- and interspecific allochronic differentiation of behaviors. Many moth species show specific daily activity rhythms in their sexual activities, some species being sexually active early at night, while others are sexually active late at night. This differentiation has been suggested to have arisen to minimize communication interference between closely related species, as co-occurring and closely related species with overlapping sex pheromone blends show a temporal differentiation in their daily sexual activities. However, the genetic differentiation of this allochronic separation has barely been examined in any species so far. In this review I summarize studies conducted on timing of sexual activities in moths, and which factors have been found to influence this timing, with the aim to identify the gaps and challenges, to unravel the possible contribution of allochronic differentiation of sexual activities in moth speciation.

Keywords: sexual communication, diurnal rhythm, female pheromone, male response, sex pheromone production

\section{INTRODUCTION}

Virtually all life on earth experiences a 24-h circadian rhythm, which affects almost all behaviors, including sexual activity and mating. Circadian rhythms are governed by an endogenous circadian clock: their behavioral patterns are maintained even in the absence of direct cues (Edery, 2000; Sandrelli et al., 2008; Bloch et al., 2013). Circadian clocks are entrained by or synchronized to the $24 \mathrm{~h}$ light/dark cycle by external environmental cues, so-called Zeitgebers, such as light and temperature. Timing of mating also follows a daily rhythm in many species, which can be crucial not only to avoid predators, but also for finding the right mating partner, as separation in timing minimizes interference in sexual signaling between species. When species distributions change due to e.g., global warming or globalization, interactions between species with the same timing of activity may cause convergence through hybridization or divergence between populations. Thus, separation in timing of mating is a powerful isolation mechanism among species, and instrumental in speciation (Tauber et al., 2003; Coyne and Orr, 2004; Devries et al., 2008; Fergus et al., 2011; Rund et al., 2012). Yet, the role and importance of allochronic differentiation in the evolution of sexual communication and speciation is almost completely unknown.

Speciation through temporal isolation between Drosophila species has been linked to circadian clock genes (Kyriacou et al., 2008), but there is no known naturally occurring dimorphism in temporal timing of mating activity in fruitflies. The ideal species to investigate the importance of timing in speciation are the larger moths and butterflies (Lepidoptera, Apoditrysia), because natural variation in timing of sexual activity has been found within and between species (see Table 1). The Apoditrysia consist of $\sim 145.000$ species, the majority of which $(\sim 120.000)$ are moths (Bazinet et al., 2013), and thus the second most diverse group of insects after the Coleoptera.

In moths, reproductive isolation mostly results from speciesspecific sex pheromone blends (e.g., Roelofs and Carde, 1971; Roelofs et al., 1974; Cardé et al., 1977; Greenfield and Karandinos, 1979; Greenfield, 1981; Haynes and Birch, 1986; El-Sayed, 2014). Moth sexual communication seems to be under strong stabilizing selection, as deviations away from the mean in female signals as well as in the male response reduces the chance of finding a mating partner (Miller and Roelofs, 1980; Collins and Cardé, 1985; Löfstedt et al., 1990; Cossé et al., 1995; Linn et al., 1997; Zhu et al., 1997; Allison and Carde, 2008). Therefore, the evolution of moth sexual communication is an evolutionary mystery (Löfstedt, 1993; Gould et al., 2009). Additional mechanisms that have been recognized to contribute to species differentiation in Lepidoptera are habitat isolation (e.g., Roelofs and Carde, 1971; Haynes and Birch, 1986; Pashley, 1986), and seasonal and circadian variation in female signaling and male response (e.g., Roelofs and Carde, 1971; Cardé et al., 1975; Teal et al., 1978; Greenfield and Karandinos, 1979; Pashley et al., 1992; Monti et al., 1995; Sauman and Reppert, 1996; Monti et al., 1997; Froy et al., 2003; Santos et al., 2007, 2011; Zhu et al., 2008; Schöfl et al., 2009; Groot et al., 2010b; Zhan et al., 2011). However, how these factors may interact has not been explored systematically. 

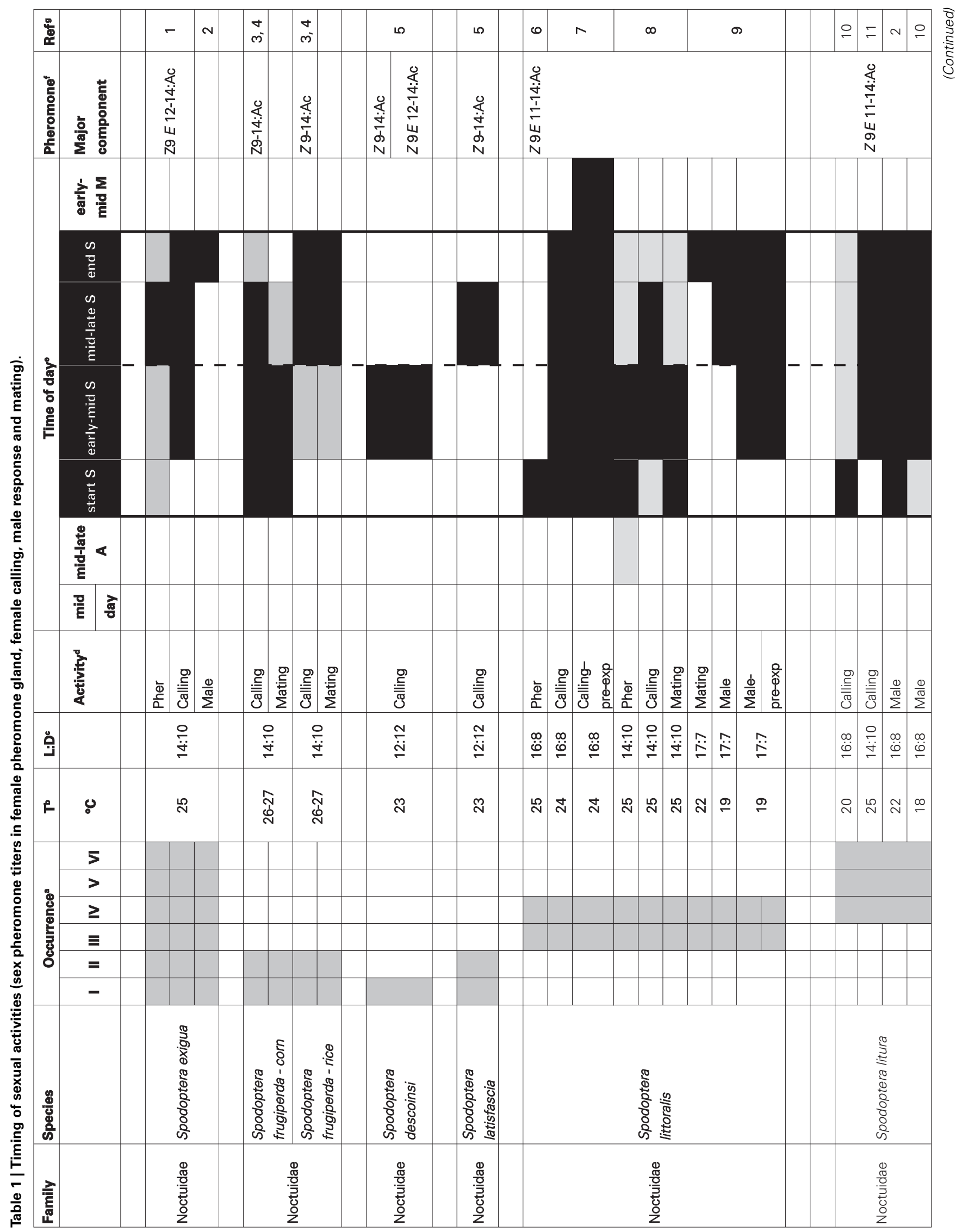


\begin{tabular}{|c|c|c|c|c|c|c|c|c|c|c|c|c|c|c|c|c|c|c|}
\hline $\begin{array}{l}\stackrel{0}{0} \\
\mathbb{0} \\
\propto x\end{array}$ & & $\sim$ & $m$ & $\underset{\leftarrow}{\Xi}$ & $\stackrel{\Omega}{\leftarrow}$ & $\stackrel{\bullet}{\leftarrow}$ & 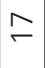 & $\stackrel{\infty}{\leftarrow}$ & $\stackrel{0}{-}$ & $\stackrel{\ominus}{\mathrm{V}}$ & $\bar{\sim}$ & 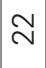 & $\stackrel{\sim}{N}$ & $\bar{\sim}$ & $\underset{N}{ }$ & $\stackrel{\leftarrow}{\sim}$ & $\stackrel{\llcorner}{\sim}$ & $\stackrel{\sim}{\sim}$ \\
\hline 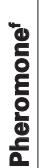 & 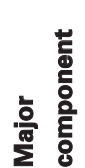 & $\begin{array}{l}0 \\
\dot{N} \\
\frac{N}{N}\end{array}$ & $\begin{array}{l}c \\
\dot{4} \\
\dot{1} \\
1\end{array}$ & & $\begin{array}{l}\frac{0}{4} \\
\dot{0} \\
\frac{1}{1} \\
\frac{5}{5}\end{array}$ & $\begin{array}{l}\frac{0}{4} \\
\dot{0} \\
\frac{1}{1} \\
\frac{1}{N}\end{array}$ & & $\begin{array}{l}\frac{0}{4} \\
\dot{0} \\
\frac{1}{5} \\
\frac{5}{5}\end{array}$ & $\begin{array}{l}7 \\
\dot{z} \\
\dot{c} \\
i \\
i\end{array}$ & & & & $\begin{array}{l}\frac{0}{4} \\
\dot{0} \\
\frac{1}{\sigma} \\
N\end{array}$ & & & & & $\frac{0}{i}$ \\
\hline
\end{tabular}

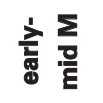

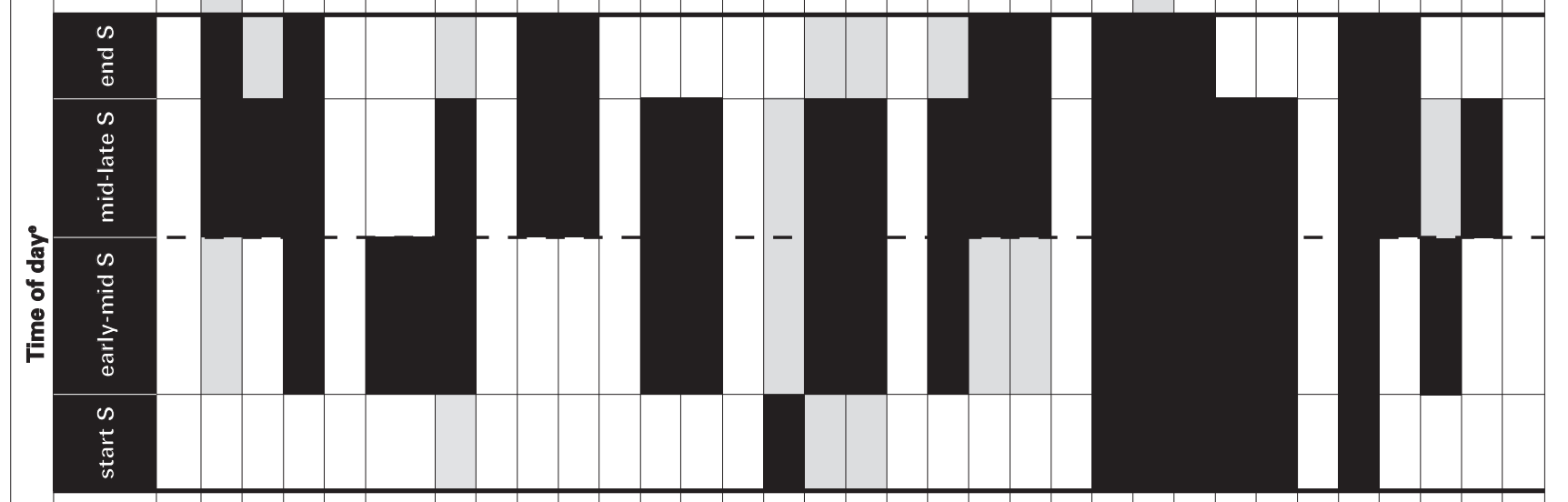

禀 $<$

ำ

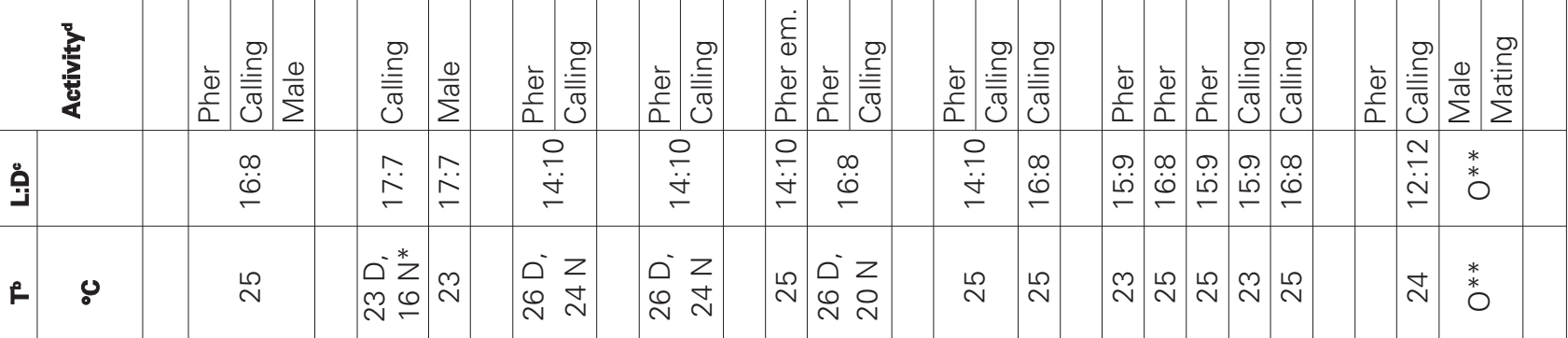

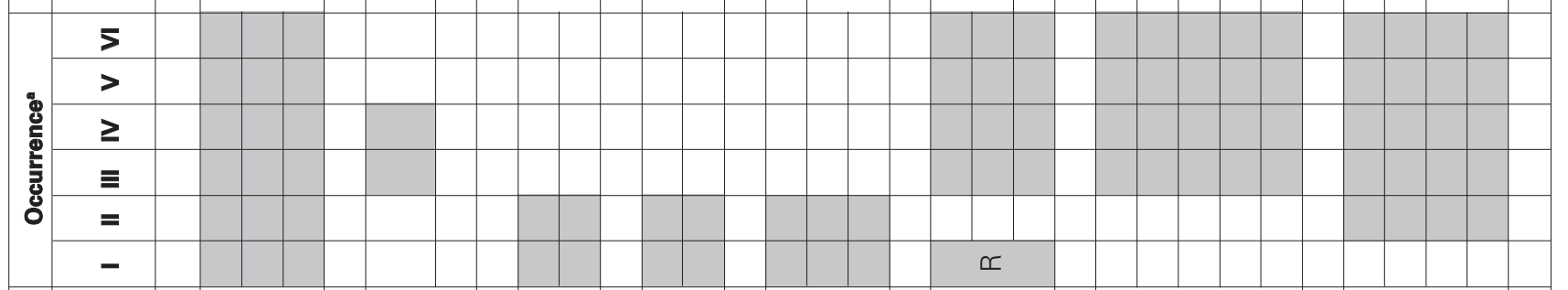

\begin{tabular}{|c|c|c|c|c|c|c|c|c|c|}
\hline & & 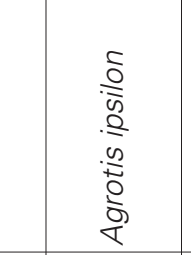 & 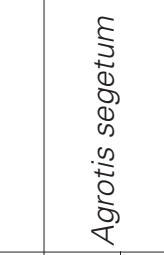 & $\begin{array}{l}0 \\
0 \\
0 \\
0 \\
0 \\
0 \\
0 \\
0 \\
0 \\
0 \\
0 \\
0 \\
1 \\
\end{array}$ & 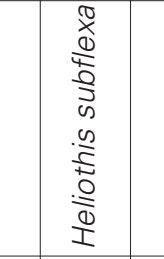 & $\begin{array}{l}0 \\
0 \\
N \\
0 \\
\frac{0}{2} \\
0 \\
0 \\
0 \\
0 \\
\frac{0}{1} \\
\end{array}$ & $\begin{array}{l}\frac{1}{1} \\
\frac{\pi}{0} \\
\frac{0}{0} \\
\frac{0}{0} \\
\frac{0}{0} \\
0 \\
0\end{array}$ & 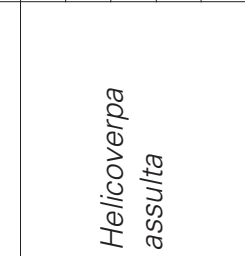 & 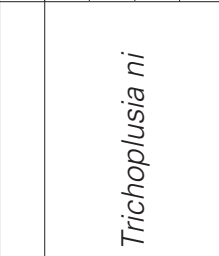 \\
\hline$\frac{\overline{0}}{\overline{0}}$ & & $\begin{array}{l}0 \\
\mathbb{0} \\
\frac{\pi}{3} \\
.0 \\
0 \\
0 \\
0 \\
\end{array}$ & \begin{tabular}{l|}
0 \\
0 \\
$\frac{\pi}{0}$ \\
3 \\
0 \\
0 \\
0 \\
2
\end{tabular} & & & & 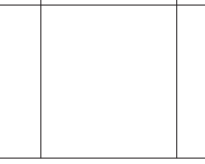 & $\begin{array}{l}0 \\
\frac{0}{0} \\
.0 \\
3 \\
0 \\
0 \\
Z\end{array}$ & $\begin{array}{l}0 \\
\frac{\pi}{\pi} \\
.0 \\
\frac{0}{3} \\
0 \\
0 \\
Z\end{array}$ \\
\hline
\end{tabular}




\begin{tabular}{|c|c|c|c|c|c|c|c|c|c|c|}
\hline$\frac{:}{\mathscr{t}}$ & & $\stackrel{\infty}{\sim}$ & $\stackrel{\infty}{\sim}$ & $\stackrel{\text { N }}{ }$ & ஓे & $\bar{m}$ & $\widetilde{m}$ & $\stackrel{M}{M}$ & & ले \\
\hline 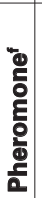 & 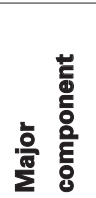 & 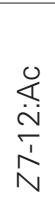 & 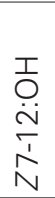 & $\begin{array}{l}0 \\
\dot{1} \\
0 \\
\frac{1}{1} \\
\overline{\bar{N}}\end{array}$ & 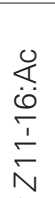 & $\begin{array}{l}\frac{0}{\overleftarrow{T}} \\
\dot{0} \\
\frac{1}{1} \\
\frac{1}{\bar{N}}\end{array}$ & $\begin{array}{l}0 \\
\dot{T} \\
\dot{0} \\
\frac{1}{1} \\
\frac{1}{N}\end{array}$ & 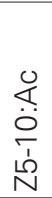 & 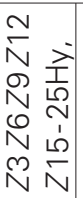 & 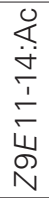 \\
\hline
\end{tabular}

\section{츨}
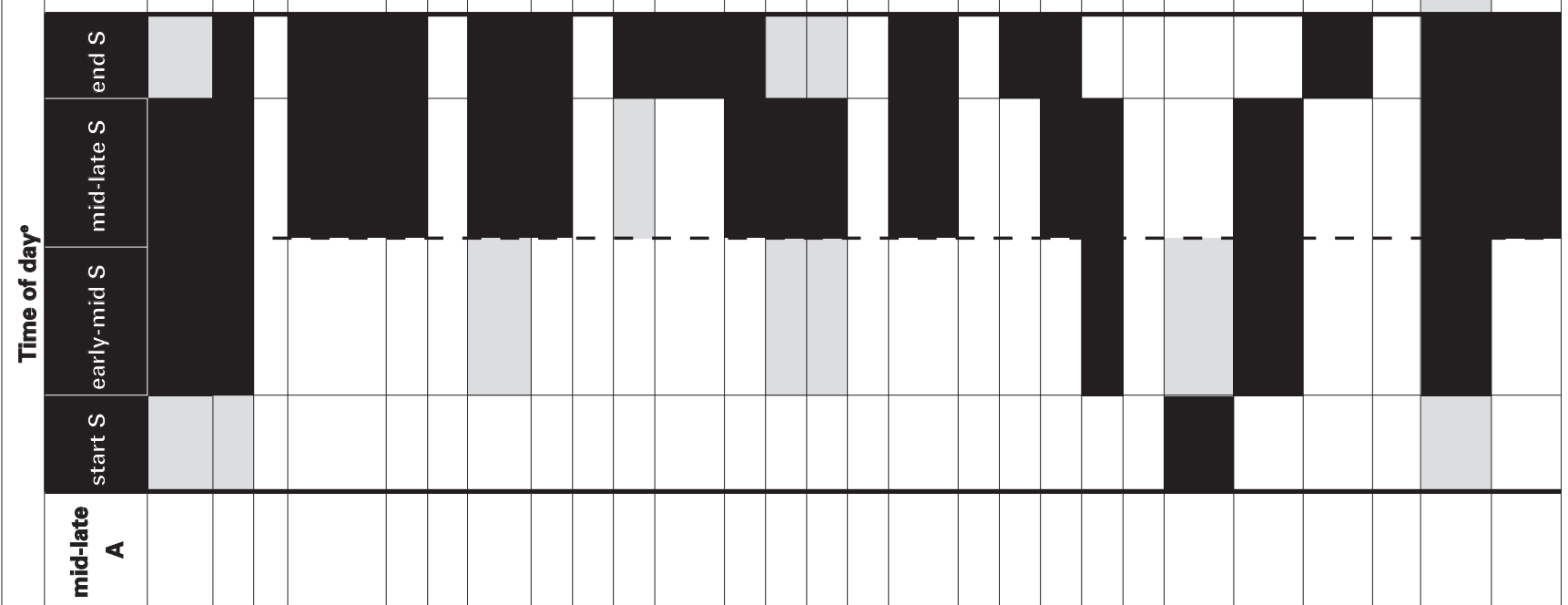

믈 형

\begin{tabular}{|c|c|c|c|c|c|c|c|c|c|c|c|c|c|}
\hline 竞 & 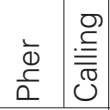 & $\frac{\bar{\Phi}}{\frac{\bar{d}}{\alpha}}$ & 岢 & & 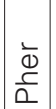 & 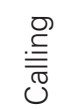 & 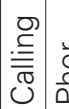 & 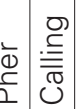 & $\frac{\text { D }}{\stackrel{\Xi}{\bar{\sigma}}}$ & $\frac{\text { D }}{\stackrel{\Xi}{\overline{\bar{\sigma}}}}$ & 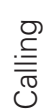 & $\frac{\bar{\Phi}}{\frac{\bar{d}}{\alpha}}$ & 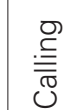 \\
\hline & $\stackrel{\circ}{\stackrel{ }{\check{夭}}}$ & $\stackrel{\circ}{\stackrel{\circ}{+}}$ & & $\begin{array}{l}\infty \\
\ddot{0}\end{array}$ & & $\begin{array}{l}\underbrace{\infty} \\
\dot{\varphi}\end{array}$ & $\begin{array}{l}\stackrel{\infty}{\dot{\varphi}} \\
\dot{\varphi}\end{array}$ & 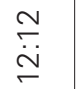 & $\begin{array}{l}\stackrel{0}{\check{+}} \\
\stackrel{+}{+}\end{array}$ & $\begin{array}{l}\stackrel{\infty}{\dot{\varphi}} \\
\dot{\varphi}\end{array}$ & 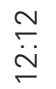 & & $\stackrel{ָ}{ָ ָ}$ \\
\hline
\end{tabular}

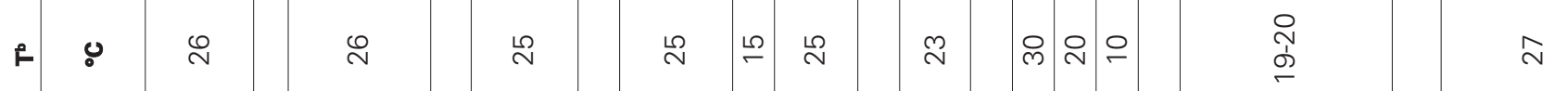

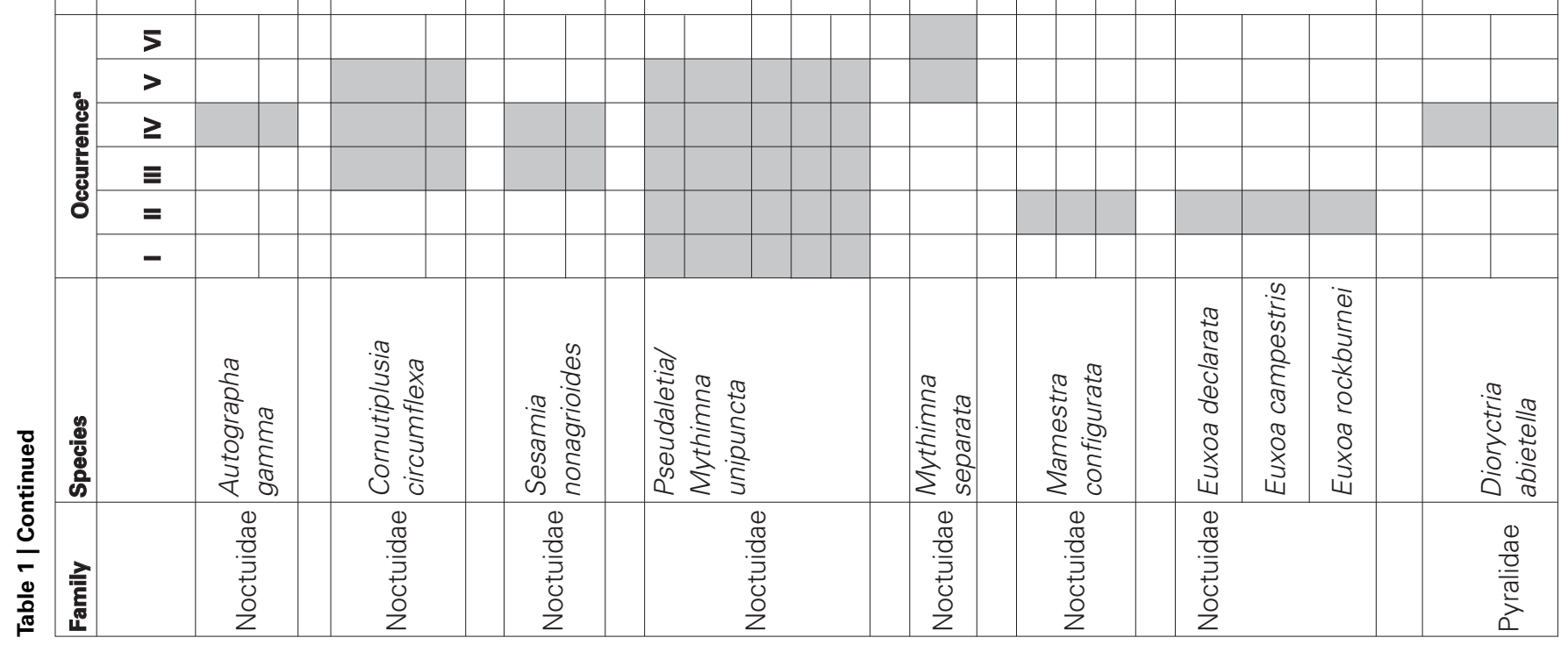



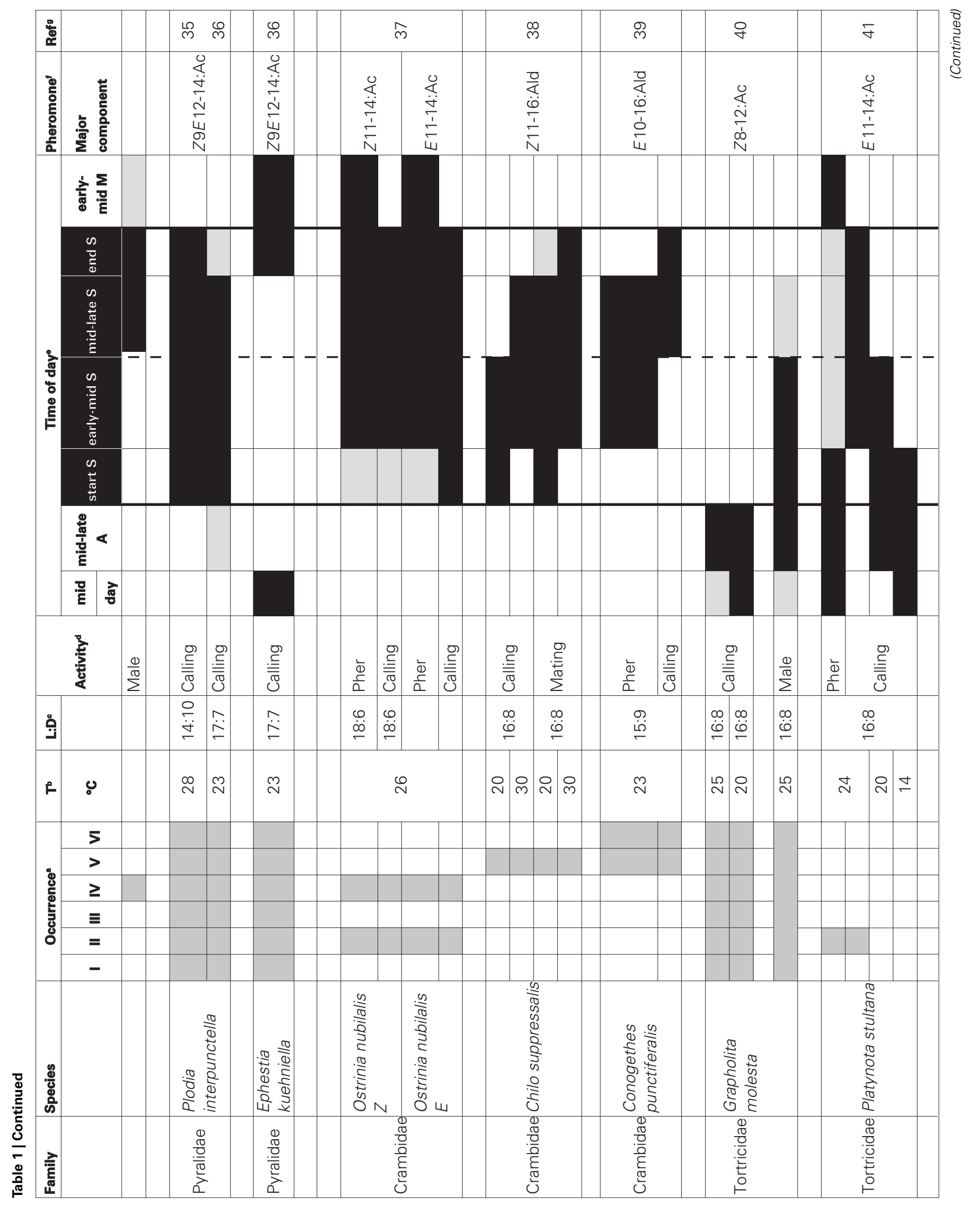

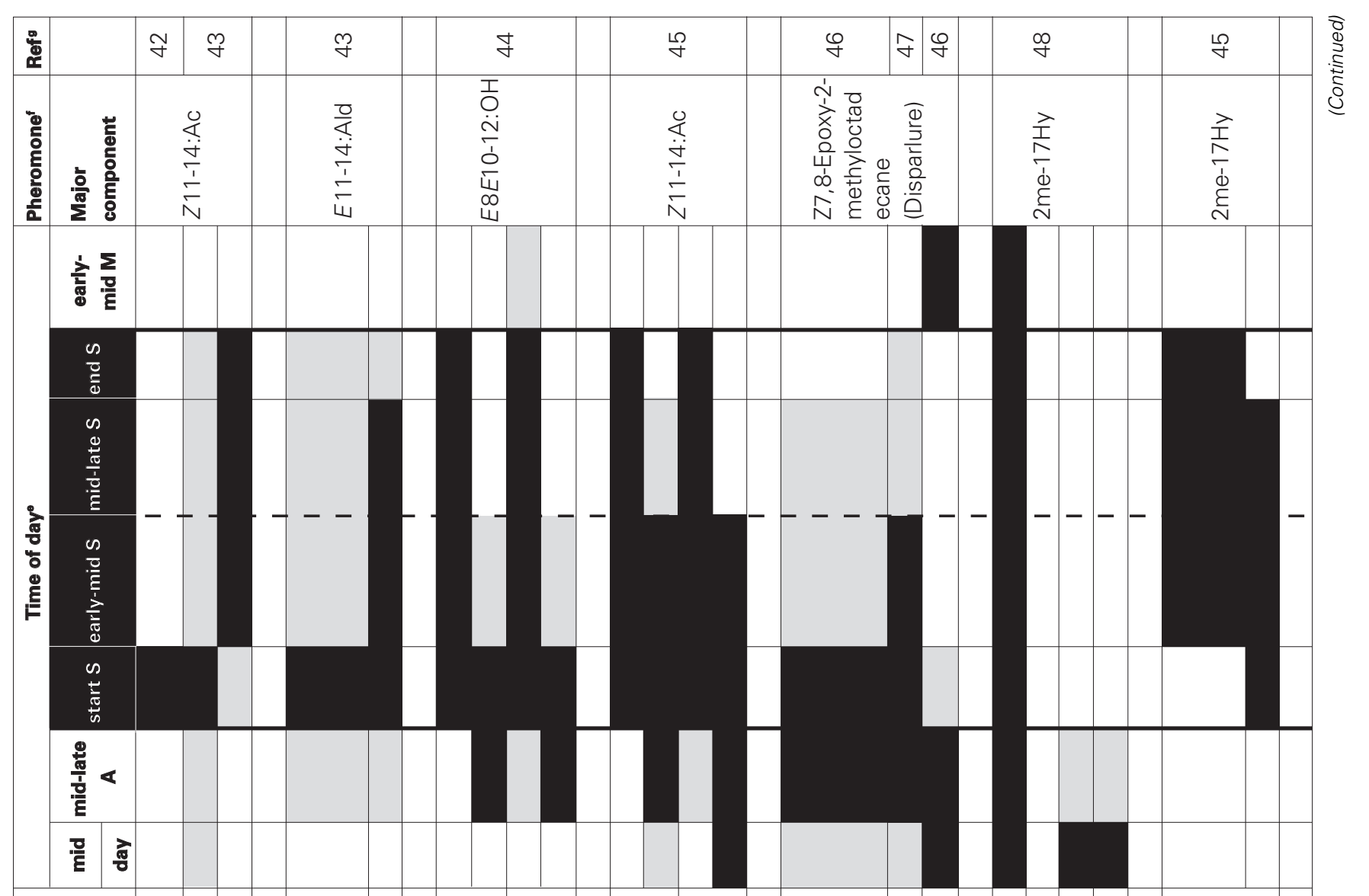

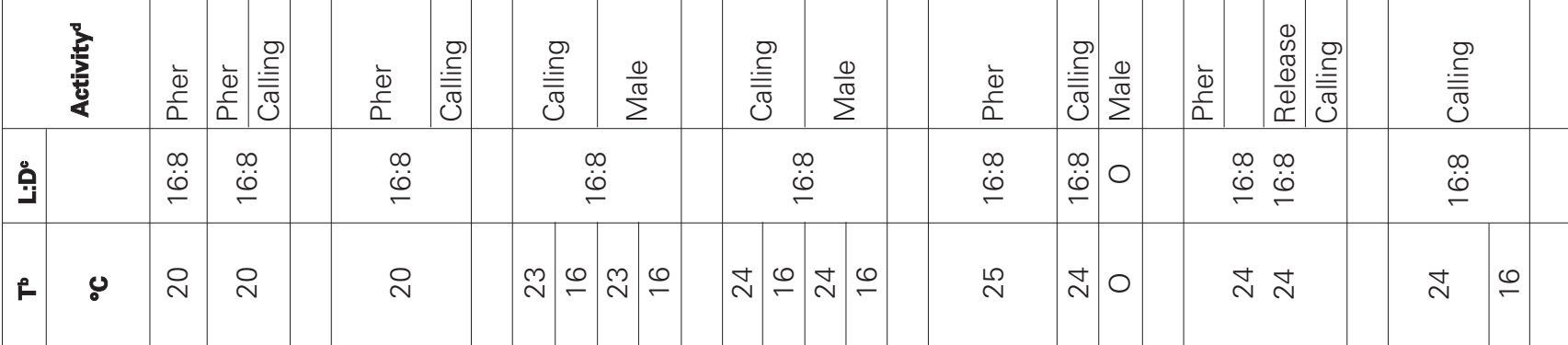

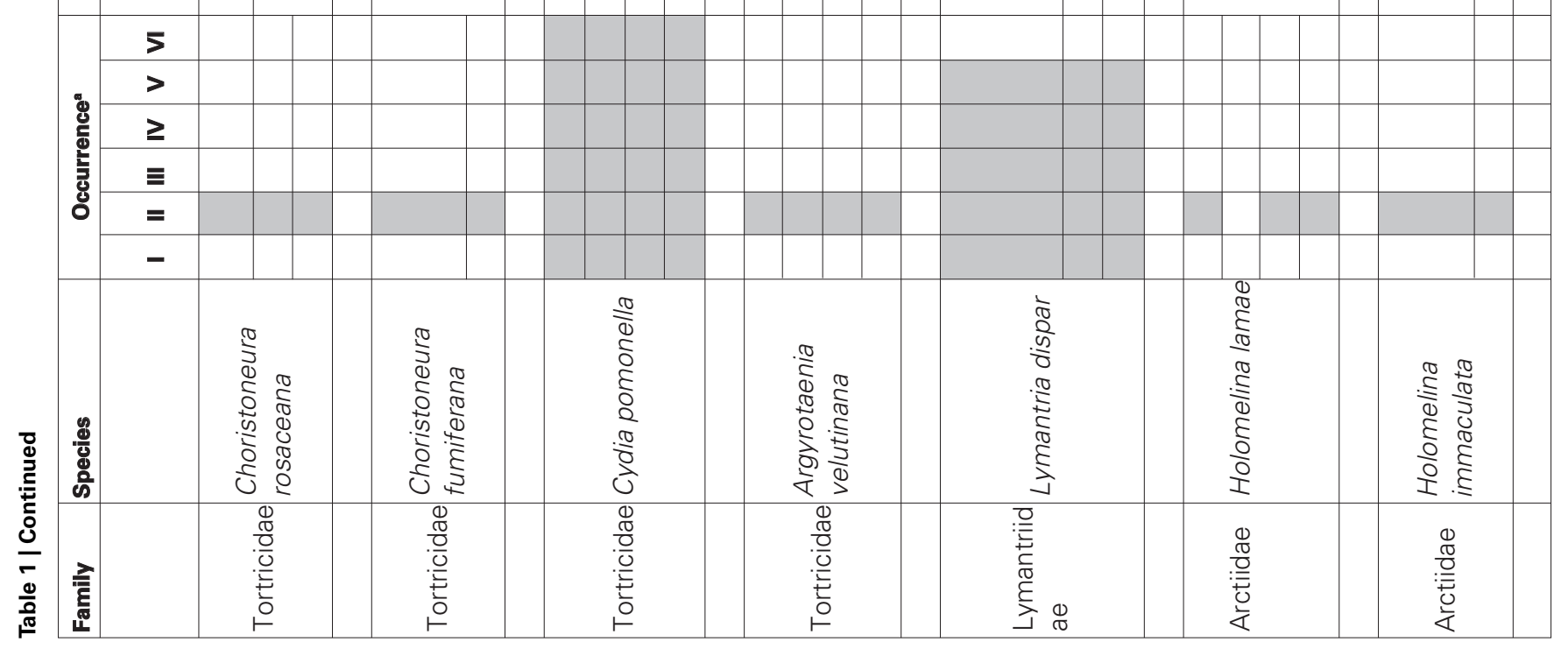




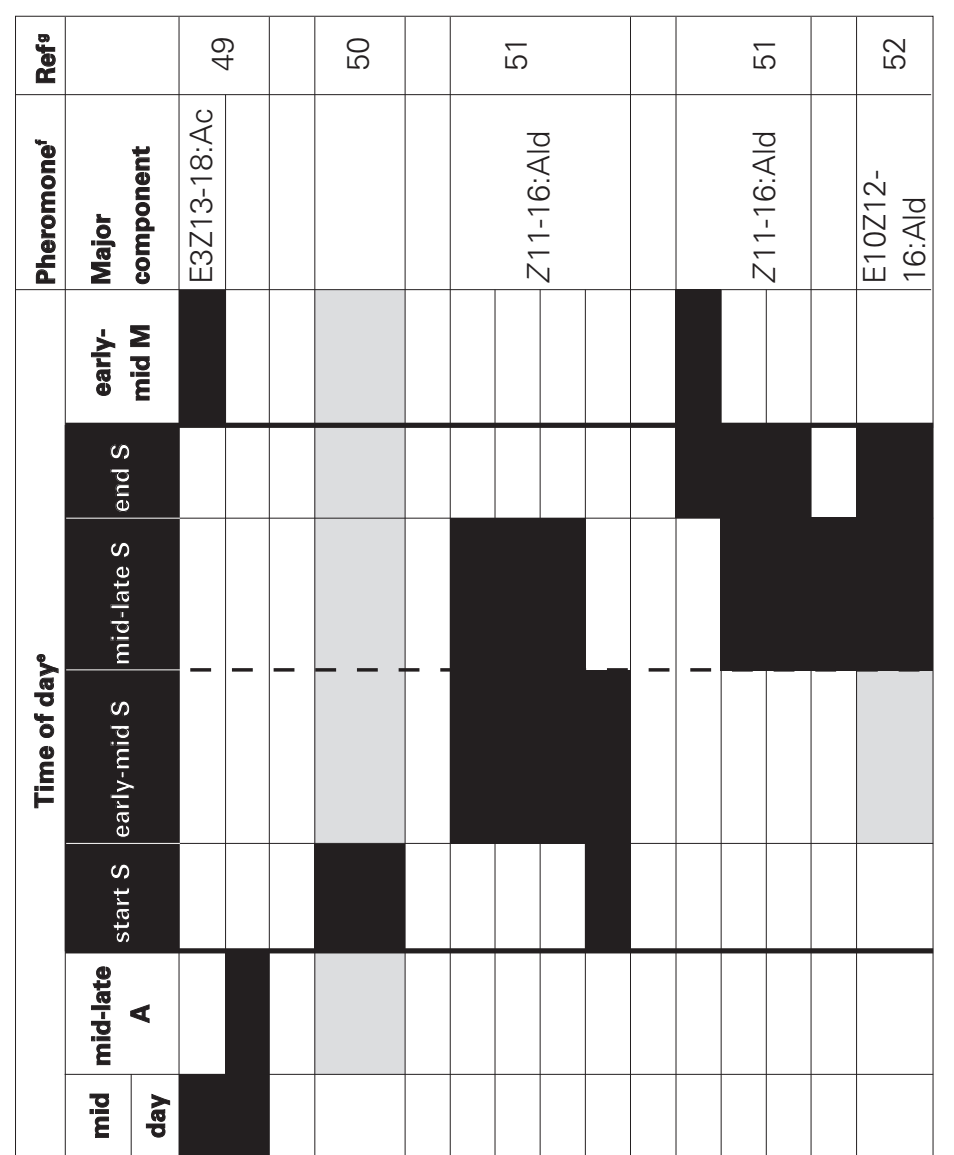

\begin{tabular}{|c|c|c|c|c|c|c|c|c|}
\hline & 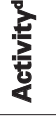 & 胥 & $\begin{array}{l}\bar{\Phi} \\
\frac{\bar{c}}{\alpha}\end{array}$ & 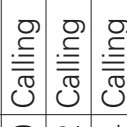 & $\frac{\frac{0}{0}}{\frac{\pi}{2}}$ & 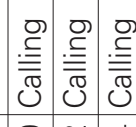 & $\frac{\frac{\infty}{\pi}}{2}$ & $\begin{array}{l}\frac{0}{\underline{\underline{\underline{E}}}} \\
\overline{\bar{N}} \\
\end{array}$ \\
\hline & & $\begin{array}{l}\dot{0} \\
\dot{\dot{\theta}}\end{array}$ & $\stackrel{\circ}{\stackrel{\ominus}{\dot{y}}}$ & 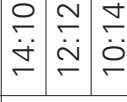 & ○ & 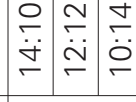 & 0 & $\begin{array}{l}\stackrel{0}{\dot{\theta}} \\
\dot{\varphi}\end{array}$ \\
\hline & 0 & 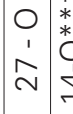 & $\stackrel{0}{N}$ & 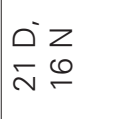 & 0 & $\begin{array}{l}\dot{0} z \\
i \leftarrow 0 \\
\end{array}$ & 0 & \\
\hline
\end{tabular}

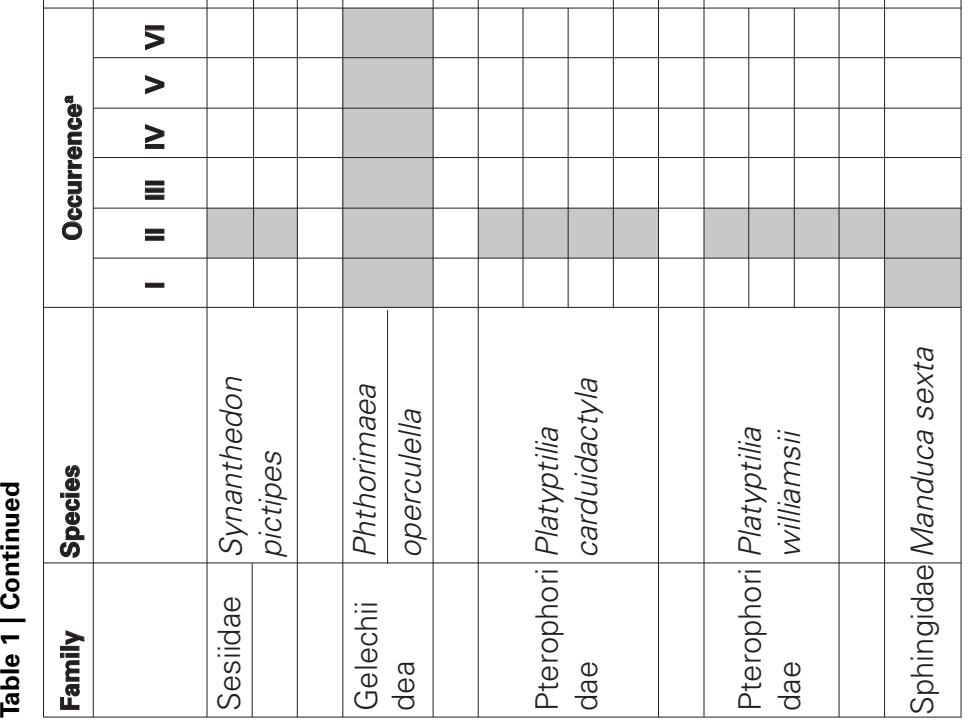

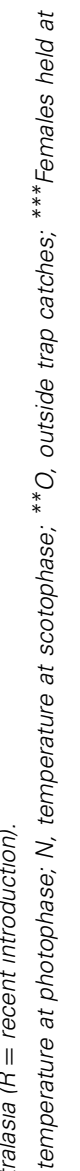

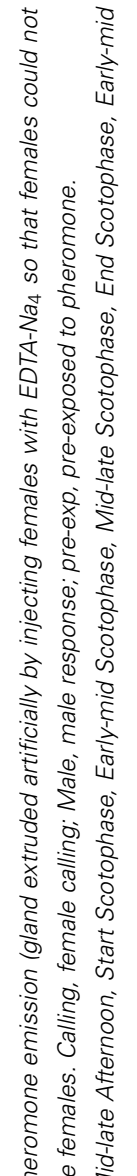

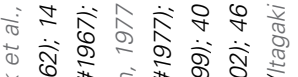

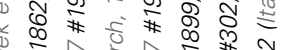

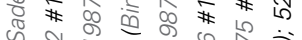

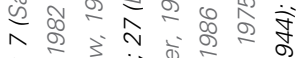
के

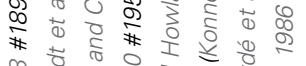

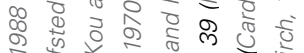
v) है

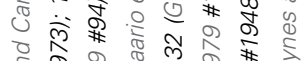

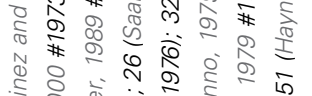

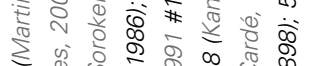

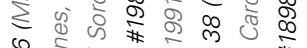

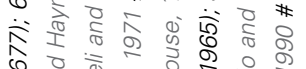
6 0

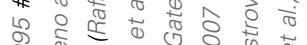

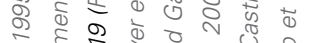

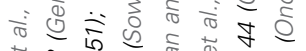

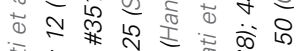

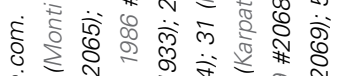

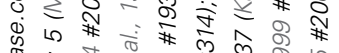

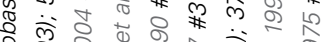
० ह $\begin{gathered}0 \\ 0\end{gathered}$ $\infty$
$\infty$

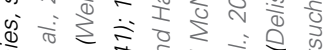

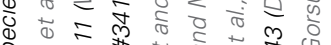

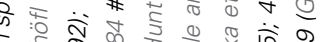
造然

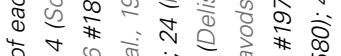

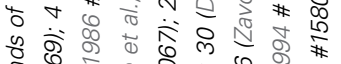
औ.

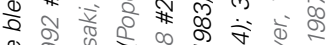

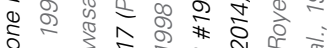

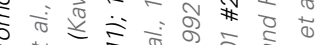

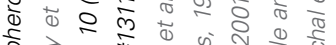

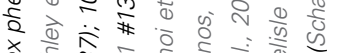

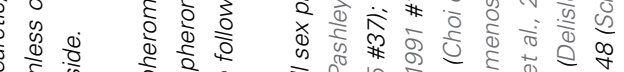
का

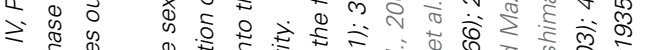

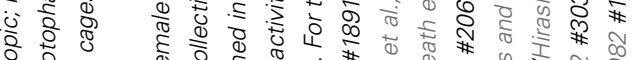

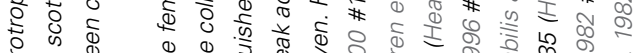

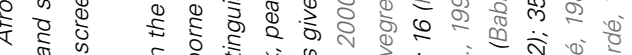

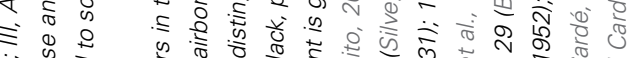

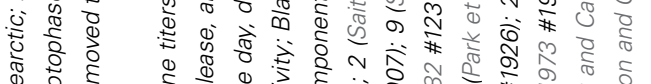

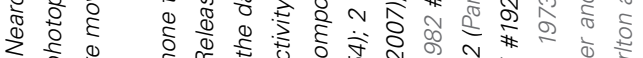

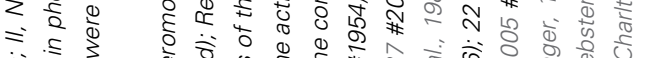

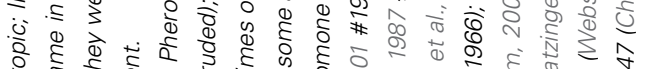

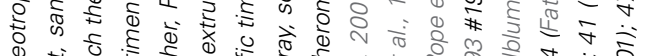

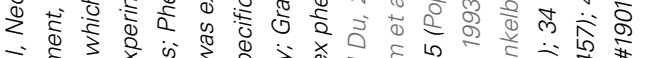
ते है

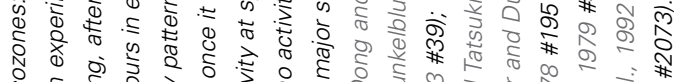

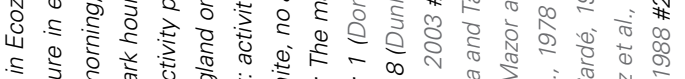

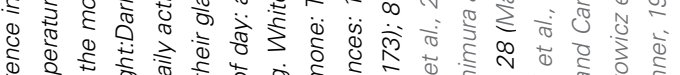

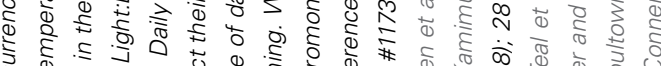

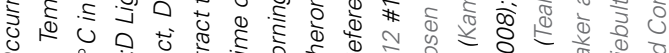

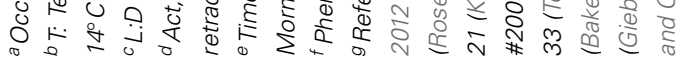


Moths show very specific daily activity patterns in their sexual activities; in some species, females start calling at the onset of scotophase and stop calling after midnight (e.g., Spodoptera frugiperda corn-strain, S. descoinsi, Agrotis segetum, Chilo suppressalis), while in other species females start calling after midnight and stop at the end of the scotophase (e.g., Spodoptera frugiperda rice-strain, S. latisfascia, Heliothis virescens, Trichoplusia ni, Pseudaletia unipuncta, Sesamia nonagrioides, Manduca sexta; see Table 1). These well-defined daily patterns have also been found for sex pheromone production (e.g., Spodoptera exigua, S. littoralis, Heliothis virescens, H. subflexa, Agrotis ipsilon, Autographa gamma) and for male response (e.g., Spodoptera exigua, S. littoralis, S. litura, Agrotis segetum, A. ipsilon, Dioryctria abietella, Cydia pomonella, Argyrotaenia velutinana (see Table 1).

Even though daily patterns of sexual activity (female calling, male response and mating) have been studied in a large number of moth species, virtually nothing is known on the evolution of allochronic differentiation, i.e., differentiation in daily patterns of sexual activity. For this we need to know the underlying physiological and genetic basis of variation in timing of daily sexual activities within and between closely related species. In this review, I summarize the knowledge that has been gathered on timing of sexual activities in moths, the identified genes and factors that have been found to affect timing of sexual behavior, which factors have been identified to affect circadian rhythms in moths, and the genetic basis of variation in timing of sexual activities. In this way, I aim to identify the gaps in our knowledge that we need to fill to understand how variation in timing of activity at night may contribute to the speciation process in moths.

\section{PHENOTYPE: VARIATION IN TIMING OF DAILY SEXUAL ACTIVITY IN MOTHS}

In the clock literature, a behavior is considered circadian only when this behavior (a) shows an endogenous free running period that lasts $\sim 24 \mathrm{~h}$, (b) shows an entrainable period, i.e., the period can be reset by external stimuli, and (c) shows temperature compensation (circadian rhythm is maintained over a broad range of temperatures). In moths, the sexual behaviors that have been shown to have a $24-\mathrm{h}$ rhythm are sex pheromone production in females, female calling, male response and mating. That this rhythm is truly circadian has been identified specifically in a few moth species, such as the cabbage looper Trichoplusia ni (Sower et al., 1971), the true armyworm Pseudaletia unipuncta (Turgeon and McNeil, 1982; Delisle, 1992), the oriental fruit moth Grapholitha molesta (Baker and Cardé, 1979), the codling moth Cydia pomonella (Castrovillo and Cardé, 1979) and the Egyptian cotton leafworm Spodoptera littoralis (Sadek et al., 2012). In these species the daily rhythm persisted in the absence of Zeitgebers, specifically light. In all moth species listed in Table 1, a daily rhythm in calling behavior has been found. Only few studies found that species become arrhythmic in constant darkness and in constant light. One such example is the Indian mealmoth Plodia interpunctella (Zavodska et al., 2012), so that its timing of sexual activities under normal L:D conditions does not seem to be regulated by an endogenous circadian clock. Maybe its endogenous clock is no longer functional, because it is a stored grain pest and is exclusively found indoors, i.e., in artificial light (Zavodska et al., 2012). Other possible explanations are that the functional clock may not remain synchronous or may be masked under constant conditions.

The calling rhythms overlap with the daily fluctuations in sex pheromone titer in some species but not in others, as described below. Since pheromone production is not always synchronous with calling behavior, these seem to be two different traits that may be regulated differently. Male response to sex pheromone has been shown to occur at specific hours at night as well (e.g., Fatzinger, 1973; Castrovillo and Cardé, 1979; Haynes and Birch, 1986; Kawasaki, 1986; Rosen et al., 2003; Silvegren et al., 2005; Merlin et al., 2007), and usually coincides with female calling time (e.g., Cardé et al., 1975; Castrovillo and Cardé, 1979), although not always (e.g., Saario et al., 1970; Cardé et al., 1974; Kawasaki, 1986). The timing of male response is thus a third trait in moth sexual communication that may have its own genetic basis.

\section{FEMALE CALLING}

Most research has been conducted on the time of female calling, probably because this is a relatively easy phenotype to measure, as females visibly extrude their sex pheromone gland from their abdomen when calling. Even though calling activity is affected by temperature, age and mating, as described below, in general some species are most active early at night, while other species start calling in the second part of the night and show peak calling activity toward the end of the scotophase. There is no phylogenetic correlation in the timing of calling, as within the same families and even genera early and late callers are found (see Table 1).

The variation in timing of female calling is most likely related to the level of overlap in sex pheromone composition between co-occurring species, because this minimizes possible communication interference (Roelofs and Cardé, 1974; Cardé et al., 1975; Baker and Cardé, 1979; Haynes and Birch, 1986). For example, Spodoptera frugiperda consists of two strains, the so-called corn and rice strain (Pashley, 1986), which co-occur throughout North and South America. Both strains differ somewhat in their sex pheromone composition (Groot et al., 2008; Lima and McNeil, 2009). However, the response of males to these differences did not differ much between the two strains, suggesting that divergence between these strains cannot be explained by their variation in sexual communication (Unbehend et al., 2013). These strains do differ significantly in their timing of sexual activity (Pashley et al., 1992; Schöfl et al., 2009), which is likely the most important contributor to their divergence (Groot et al., 2008, 2014). Other examples of overlapping pheromone but non-overlapping timing of sexual activity are Spodoptera descoinsi and S. latisfascia (Monti et al., 1995), Platyptilia carduidactyla and P. williamsii (Haynes and Birch, 1986), Euxoa declarata, E. campestris, and E. rockburnei (Teal et al., 1978) and Lymantria monacha and L. dispar (Roelofs and Cardé, 1974). The latter two species co-occur in Europe, where L. dispar is sexually active during the day, while L. monacha is active at dusk and at night (Roelofs and Cardé, 1974). In the USA, where L. dispar was introduced and L. monacha is absent, the timing of sexual activity in L. dispar expands into the night, which makes it likely that selection pressure from L. monacha has restricted the timing of sexual activity of $L$. dispar in Europe to the daytime (Haynes and Birch, 1986). 
Conversely, examples of co-occurring species with overlapping timing of activity but non-overlapping sex pheromone are the Eand Z-strain of Ostrinia nubilalis (Karpati et al., 2007), Heliothis virescens and H. subflexa (Heath et al., 1991; Groot et al., 2009) and Helicoverpa armigera and H. assulta (Kou and Chow, 1987; Rafaeli and Soroker, 1989; Kamimura and Tatsuki, 1993). In the latter two species groups, one of the species (Heliothis subflexa and Helicoverpa assulta) produce and emit not only attractive sex pheromone compounds, but also compounds that specifically inhibit the attraction of heterospecific males, i.e., Heliothis virescens and Helicoverpa armigera, respectively (Kamimura and Tatsuki, 1993; Boo et al., 1995; Groot et al., 2006). The presence of such inhibitory compounds in the sex pheromone blend indicates that communication interference is an important selection force in the evolution of moth sexual communication (Groot et al., 2006).

Variation in female calling may also be related to the presence and timing of activities of predators and parasitoids (Baker and Carde, 1978; Cardé and Baker, 1984; Acharya and McNeil, 1998; Skals et al., 2005; Conner and Corcoran, 2012; Corcoran and Conner, 2012). A few studies have shown that attraction of male moths to female pheromone is disrupted by ultrasounds, indicating the presence of predatory bats (Baker and Carde, 1978; Acharya and McNeil, 1998), although there can be a trade-off in male response to pheromone and evasive behavior to sounds from predators (Skals et al., 2005). However, whether and to what extent timing of moth sexual activity is driven by timing of activity of predators and parasitoids is difficult to assess. In addition, female pheromone may adhere to plant leaves, so that day-active parasitoids may still home in on the eggs oviposited by night-active female moths, as the pheromone gland surrounds the ovipositor (Noldus et al., 1991; Xu et al., in press).

\section{SEX PHEROMONE PRODUCTION IN FEMALES}

In moths, pheromone production in females has been shown to be regulated by Pheromone Biosynthesis Activating Neuropeptide (PBAN) (Raina et al., 1989; Rafaeli and Jurenka, 2003; Jurenka, 2004; Jurenka and Rafaeli, 2011); (but see Tang et al., 1989). This neuropeptide is produced by three groups of neurons present in the suboesophagal ganglion (SOG) and released via the the corpus cardiacum (CC) into the hemolymph (Jurenka, 2004). When PBAN binds to the PBAN receptor (PBANr) in the sex pheromone gland, a calcium channel is opened and the influx of $\mathrm{Ca}^{2+}$ initiates pheromone production (Rafaeli et al., 2007) (see Figure 1 for a simplified schematic overview). The sex pheromone precursors stearic acid, palmitic acid, and myristic acid may be stored first as triacyl glycerides, or directly converted to the end products, which are generally aldehydes, alcohols and acetate esters (Jurenka, 2004). PBAN may act on a late stage in the biosynthetic pathway, by activating fatty acid reduction (Arima et al., 1991) or by mobilizing the fats stored in triacylglycerols (Matsumoto et al., 2010) (pathway 1 in Figure 1), or PBAN may control the early stage of pheromone biosynthesis (pathway 2 in Figure 1) (Eltahlawy et al., 2007; Tsfadia et al., 2008; Jurenka and Rafaeli, 2011).

Whether the action of PBAN is a circadian humoral regulator seems to depend on whether the circadian rhythm of PBAN levels in the hemolymph is synchronized with pheromone production. In a number of moth species, sex pheromone production in females has been found to occur de novo every day, and has been found to be synchronous with female calling (e.g., Fatzinger, 1973; Coffelt et al., 1978; Pope et al., 1982; Raina et al., 1986, 1989; Rafaeli and Soroker, 1989; Raina, 1993; Ramaswamy et al., 1995; Iglesias et al., 1999, 2002; Foster, 2000; Dong and Du, 2001; Rafaeli and Jurenka, 2003; Xiang et al., 2010). However, in other species pheromone production seems to occur at different times, usually before calling (Coffelt et al., 1978; Bjostad et al., 1980; Webster and Cardé, 1982; Konno, 1986; Schal et al., 1987; Giebultowicz et al., 1992). For example, in Platonota sultana, pheromone levels were high before females started calling and then decreased significantly once the females called (Webster and Cardé, 1982). Alternatively, the pheromone levels in the gland may be relatively constant day and night, e.g., in Trichoplusia ni, Pectinophora gossypiella, and Argyrotaenia velutinana (Hunt and Haynes, 1990; Jurenka et al., 1994; Rafaeli and Klein, 1994). Hence, in these species biosynthesis of sex pheromone seems to occur independently from when females are actually calling, suggesting that pheromone can be synthesized rapidly during calling (Schal et al., 1987) and that pheromone can be stored in the gland before calling.

Pheromone precursors can be stored in the gland as glycerolipids, as mentioned above, which may be mobilized for pheromone biosynthesis, at least in Bombyx mori (Fonagy et al., 2001; Matsumoto et al., 2002, 2010). However, in other species (Argyrotaenia velutinana, Ostrinia nubilalis, and Heliothis virescens) these precursors seem to be dead end stores for excess precursor acids and not used for pheromone biosynthesis (Bjostad et al., 1987; Foster, 2004; Foster and Anderson, 2012). These differences are likely due to nutrient intake and pheromone biosynthesis control via PBAN: in B. mori, females do not feed and PBAN seems to act on a late stage in the biosynthetic pathway (Arima et al., 1991; Matsumoto et al., 2010). In H. virescens, females do feed on nectar, and can thus replenish carbohydrate resources to start pheromone biosynthesis from the basic building blocks acetyl CoA and malonyl CoA (Jurenka, 2003; Foster, 2009). In addition, in heliothine moths PBAN controls the early stage of pheromone biosynthesis (Eltahlawy et al., 2007; Jurenka and Rafaeli, 2011) and pheromone production coincides with female calling (Pope et al., 1982; Heath et al., 1991). Thus, it seems that in species that store pheromone precursors, pheromones biosynthesis is not in phase with female calling, while in species without such storage and with de novo synthesis every night, pheromone biosynthesis is in the same phase as female calling.

\section{MALE ACTIVITY AND RESPONSE}

That male response to female sex pheromone shows a circadian rhythm in moths has been shown for Cydia pomonella, Agrotis segetum, Trichoplusia ni, and Spodoptera littoralis (Castrovillo and Cardé, 1979; Linn et al., 1996; Rosen et al., 2003; Silvegren et al., 2005; Merlin et al., 2007): in the absence of Zeitgebers, these species showed persistent rhythms in their attraction to sex pheromone. Of course, sexual communication can only be effective if female calling and male response are synchronized. Such synchronization reduces metabolic costs and likely also predation 


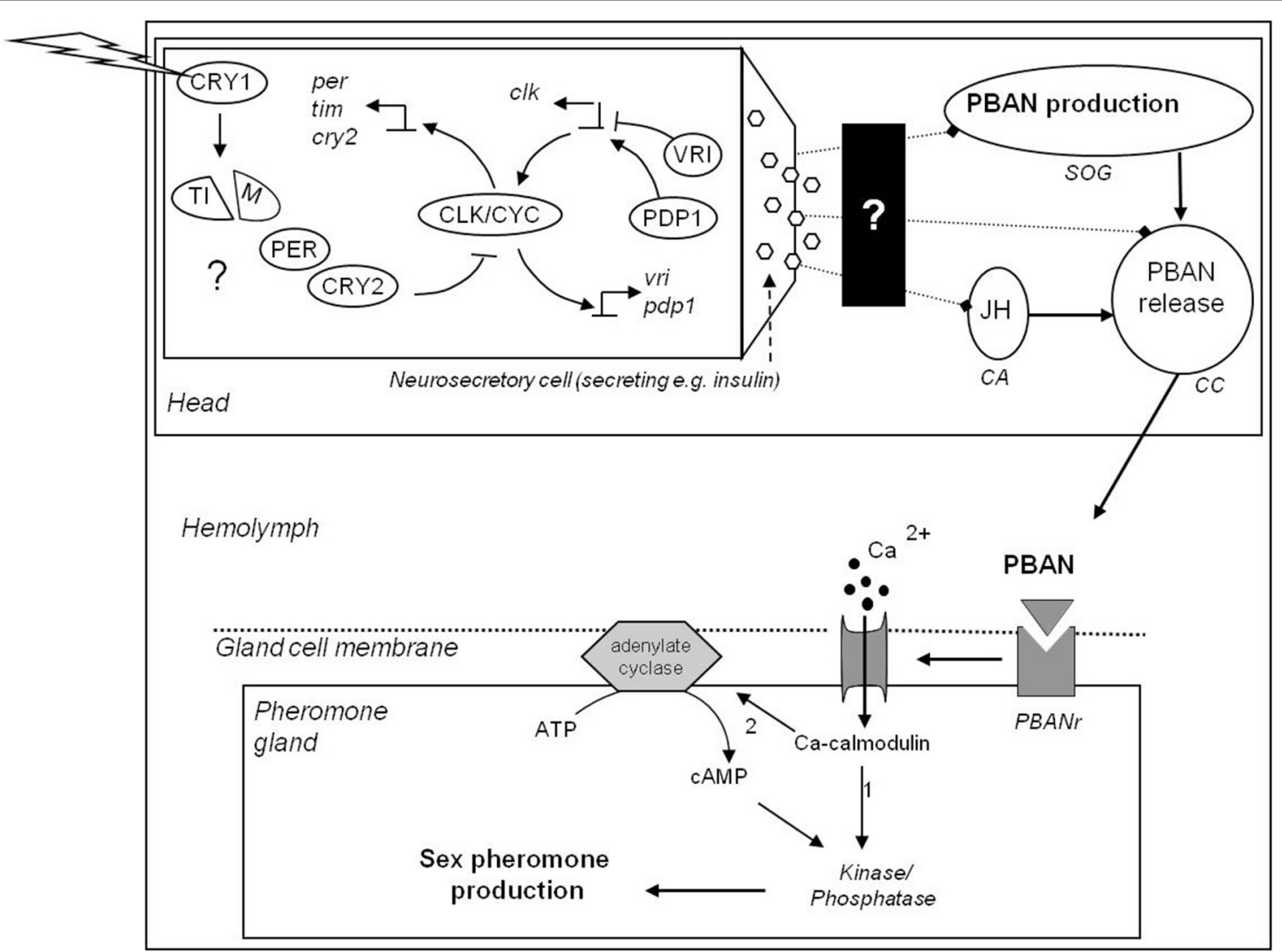

FIGURE 1 | Simplified flow diagram of circadian feedback loops in neurosecretory cells and their possible regulation of moth sex pheromone biosynthesis. Question marks are the outstanding questions for moths. Clock genes are expressed in neurosecretory cells [pars lateralis (PL) and pars intercerebralis (PI)], but maybe also in the subesophagal ganglion (SOG), corpus cardiacum (CC) and corpus allatum (CA) (see Sandrelli et al., 2008). CRY1 is activated by light and degrades TIM. CRY2 is light-independent and inhibits CLK/CYC mediated expression of per/tim. In both day-active and night-active insects, per and tim are transcribed mostly at night. The neurosecretory cells innervate the CA, CC and/or the SOG (indicated with dotted lines with diamond) (Bloch et al. 2013), activating JH production in CA. Exactly how this activation occurs is still a black box, although it is known that insulin is involved (Reppert et al., 2010). PBAN is produced in the SOG, likely continuously, so that it accumulates during the photophase in some moths (Rafaeli, 1994). PBAN transport to and its release from the $\mathrm{CC}$ into the hemolymph is regulated by a circadian clock (Rafaeli, 1994), but how exactly is not known. When PBAN binds to the PBAN receptor (PBANr, a G-protein coupled receptor) in the pheromone gland cell membrane, a Ca-channel opens. The influx of $\mathrm{Ca}^{2+}$ either stimulates phosphatases directly (in B. mori; path (1) or activates CAMP via adenylate cyclase, which in turn stimulates phosphatases and/or kinases (in Heliothines; path (2), after which pheromone is produced (either starting with acetyl CoA and malonyl CoA or acting on the final reduction of the pheromone precursors) (Blomquist and Vogt, 2003; Jurenka, 2004). The neurosecretory secretions act similarly as is shown for PBAN, i.e., by binding to receptors they cause a $\mathrm{Ca}^{2+}$ influx, which (de)phosphorylates proteins in the cytoplasm, affecting transcription of e.g., clock genes. Overall, it is not clear yet whether circadian rhythms in moth behavior or physiology are regulated by peripheral clocks and/or central pacemakers that act via neuronal and/or via endocrine signaling pathways, or through interactions between these factors (Bloch et al., 2013). See text for further explanations.
(Cardé and Baker, 1984; Acharya and McNeil, 1998; Silvegren et al., 2005; Skals et al., 2005). However, a wider temporal male response window could be advantageous for males to locate early as well as late calling females (Linn, 1997). As mentioned above, the timing of male usually coincides with female calling time (e.g., Cardé et al., 1975; Castrovillo and Cardé, 1979), but exceptions do occur (e.g., Saario et al., 1970; Cardé et al., 1974; Kawasaki, 1986).

\section{GENOTYPE: IDENTIFIED GENES AND FACTORS UNDERLYING CIRCADIAN RHYTHMS OF SEXUAL BEHAVIOR THE CORE CIRCADIAN CLOCK: TWO INTERACTING FEEDBACK LOOPS}

The genes underlying variation in circadian rhythms of behavior in general has been extensively studied in Drosophila melanogaster, mostly through mutagenesis experiments (Konopka and Benzer, 1971; Hall, 2003; Zhang and Kay, 2010). The center of the clock represents the activation of period (per) and timeless (tim) and the binding of protein dimers to E-boxes that are found in the promoter region of many circadian genes, e.g., per, tim, vrille, PAR domain protein $1 e$ (pdp1e) (Peschel and Helfrich-Forster, 2011). In D. melanogaster, two interlocked feedback loops form the clock gene network, centered around the rhythmic expression of $c l k$ (Cyran et al., 2003; Hardin, 2005). In one loop, per and tim transcription is activated by the binding of the CLOCK/CYCLE (CLK/CYC) to their promoter. After translation, PER/TIM heterodimerize in the cytoplasm and are translocated to the nucleus where PER 
inhibits CLK/CYC activity in a $\sim 24 \mathrm{~h}$ cycle (see also Figure 1). In a stabilizing loop regulating clock expression levels, vrille and $p d p 1$ are transcribed. The expression of clock is repressed by VRILLE that binds to the VRILLE/PDP1 binding box in the clock promoter, after which PDP1 accumulates and substitutes VRILLE in binding to the VRILLE/PDP1 binding box, which promotes clock expression (Cyran et al., 2003; Hardin, 2005).

In Lepidoptera, most work on clock genes has been conducted in the moth Anthereae pernyi (Prestwich et al., 1986; Reppert et al., 1994; Levine et al., 1995; Sauman and Reppert, 1996, 1998; Gotter et al., 1999; Sauman et al., 2000; Chang et al., 2003) and Danaus plexippus (Froy et al., 2003; Sauman et al., 2005; Zhu et al., 2008, 2009; Zhan et al., 2011), as well as in Bombyx mori (Sehadova et al., 2004) and Manduca sexta (Wise et al., 2002; Schuckel et al., 2007). These studies have focused on verification of the identified clock genes from Drosophila in lepidopteran species. In these comparative analyses, some essential differences have been found, as described below.

In Drosophila melanogaster, there are at least three light-input pathways for the daily light-input entrainment (Helfrich-Forster et al., 2001), one of which is through the circadian photoreceptor Cryptochrome (CRY) that is acting in the pacemaker cells themselves (Emery et al., 1998), and mediates the lightdegradation of TIM (Young et al., 1996; Ivanchenko et al., 2001; Hall, 2003; Peschel et al., 2006). In constant light, flies become arrhythmic, which is likely due to light-dependent degradation of TIM (Konopka et al., 1989). TIM stabilizes PER in the cytoplasm after dark (see review Peschel and Helfrich-Forster, 2011).

In Lepidoptera (as well as in some other insects) there are two cryptochromes, CRY1 and CRY2 (Zhu et al., 2005, 2008) instead of one. CRY1 (CRY-d) is similar to the Drosophila CRY and seems to have a similar function as in the flies, while CRY2 (CRY-m) is homologous to vertebrate CRY and functions as a transcriptional repressor to per transcription (Merlin et al., 2013), replacing the function of PER (see review Sandrelli et al., 2008). Whether TIM has a similar function in Lepidoptera as described in Drosophila, i.e., stabilizing PER, seems thus unlikely but remains to be investigated.

Also, in contrast to Drosophila, PER has not been found in the nucleus in brain neurons in the investigated lepidopteran species so far (Sandrelli et al., 2008), although Schuckel et al. (2007) found it in the nucleus of olfactory receptor neurons in Manduca sexta. The inability to find PER in the nucleus in other studies may be due to a technical problem, e.g., a problem with the antibodies used (Schuckel et al., 2007). However, this is an unsatisfactory explanation as no clock proteins except monarch CRY2 has ever been found nuclear, and in Danaus plexippus all immunocytochemistry experiments, including those on PER, have been performed with species-specific antibodies. In nightactive moths, it seems likely that activation of some core clock genes are reversed or that oscillators are differently coupled compared to day-active insects, such as Drosophila and day-active butterflies, although per and tim transcription levels are highest at night both in day- and night-active insects (Giebultowicz, 2000).

\section{LOCALIZATION OF THE CLOCK CELLS}

Clock genes are expressed in the central nervous system in the brain, where the circadian master clock is located (Sandrelli et al., 2008). In Drosophila, the photoreceptors are located in many clock neurons in the brain and directly respond to light stimuli (see review Peschel and Helfrich-Forster, 2011). The physical location of the Lepidoptera clock, at least in the species investigated, is in the dorsolateral protocerebrum, specifically in four large neurons clustered in the pars lateralis (Truman, 1972, 1974; Wise et al., 2002; Sehadova et al., 2004; Sauman et al., 2005; Zhu et al., 2008). These neurons are type 1a neurosecretory cells. In Danaus plexippus all four neurons co-express tim and cry2, while two of the four neurons also co-express per and cry1 (Wise et al., 2002; Sehadova et al., 2004; Sauman et al., 2005; Zhu et al., 2008)

In insects, clocks in peripheral tissues (antennae, gut, reproductive tissues and even epidermis) also function independently of the core clock (Giebultowicz, 2000, 2001; Helfrich-Forster, 2004). For example, rhythmic release of sperm bundles has been found in the moth species Cydia pomonella (Gvakharia et al., 2000), Lymantria monacha (Giebultowicz et al., 1989; Riemann and Giebultowicz, 1991), and Spodoptera littoralis (KotwicaRolinska et al., 2013). Per-positive epithelial cells that surround the vas deferens lumen were found to have a daily cycle of secretory activity, and this circadian activity seems vital in moths, as disruption of this rhythm through constant light leads to male sterility (Giebultowicz et al., 1990). Per is also present at the base of chemoreceptor cells in the antennae (Plautz et al., 1997). In the monarch butterfly, antennal circadian clock coordinates sun compass orientation during migration (Merlin et al., 2009; Reppert et al., 2010), which seem to oscillate independently from the brain, as clock protein and mRNA levels oscillated even in vitro and continued to respond to light (Merlin et al., 2009; Reppert et al., 2010).

\section{GENE REGULATORS: ENDOCRINE SIGNALS}

The general regulators of clock genes are endocrine signals that, when bound to receptors (generally G-protein coupled receptors), cause an influx of $\mathrm{Ca}^{2+}$ or $\mathrm{K}^{+}$, which (de)phosphorylates clock proteins in the cytoplasm, which in turn changes their stability and causes their degradation (Hardin, 2011; Peschel and Helfrich-Forster, 2011). Several kinases have been identified that phosphorylate PER, CLK, and TIM in Drosophila (Hardin, 2011).

The main neurotransmitter that has been studied most thoroughly is Pigment Dispersing Factor (PDF), which is a well-conserved neuropeptide present in master clock neurons of all insects studied so far, including Blattodea, Coleoptera, Hymenoptera and Lepidoptera (Hermann et al., 2013). The PDF receptor is located on most clock neurons (Shafer et al., 2008), and is considered to be the main output factor of the clock, acting as a neuromodulatory as well as a synchronizing signal between different clock neuron clusters (Petri and Stengl, 1997; Helfrich-Forster, 1998; Schneider and Stengl, 2005; Shafer et al., 2008). In Drosophila, PDF is co-expressed with PER, but this is not the case in other insects (Zavodska et al., 2003; Hermann et al., 2013). Zavodska et al. (2012) examined the location of PDF in the two moth species Plodia interpunctella and Ephestia 
kuehniella, and found in both species PDF-positive cells in the pars intercerebralis, the superior lateral protocerebrum, the optic lob and the suboesophagal ganglion. However, in P. interpunctella no PDF-stained cells were found in the interior medial protocerebrum, which may at least partly be correlated to the fact that this species is arrhythmic or not synchronized in constant darkness and in constant light (Zavodska et al., 2012).

As mentioned in $1 \mathrm{~b}$, sex pheromone production is regulated by PBAN. At what time of the day or night PBAN is released from the SOG seems to depend on juvenile hormone (JH) (Cusson and McNeil, 1989; Gadenne et al., 1993; Cusson et al., 1994). JH is synthesized and released from the corpora alata (CA), which is innervated by neurosecretory cells that have their cell bodies in the brain, the corpora cardiaca (CC), or the suboesophagal ganglion (SOG) (Bloch et al., 2013). JH biosynthesis can be regulated via direct or indirect neuronal pathways coming from cells in the circadian network (Bloch et al., 2013) (see also Figure 1). In other insects, $\mathrm{JH}$ regulates production or release of sex attractants, i.e., in cockroaches (Schal et al., 1997) and bark beetles (Seybold and Tittiger, 2003). Also in some migratory moth species there is evidence that $\mathrm{JH}$ regulates PBAN biosynthesis or release (Cusson and McNeil, 1989; Gadenne et al., 1993; Picimbon et al., 1995). However, in non-migratory moth species, the exact role of $\mathrm{JH}$ in regulating daily sex-pheromone production is still poorly understood (Bloch et al., 2013). In the non-migratory Helicoverpa armigera, $\mathrm{JH}$ has been shown to prime the pheromone gland just before the females emerge, i.e., only during development (Fan et al., 1999).

$\mathrm{JH}$ may be involved in the circadian modulation of the male response to the female calling signals, as has been found in Agrotis segetum (Rosen et al., 2003). In the related species A. ipsilon, $\mathrm{JH}$ has been found to regulate male sensitivity to female sex pheromone in the antennal lobes, but not in the antenna (Anton and Gadenne, 1999). However, it is not clear whether JH titers in male Agrotis moths vary during the day. In addition, the temporal relationship between peak $\mathrm{JH}$ titers and male flight activity may differ between species. For example, the crickets Gryllus rubens and Scapteriscus vicinus have similar diurnal $\mathrm{JH}$ titer profiles, while G. rubens is active throughout the night and S. vicinus is only active for a short period directly after sunset (Bloch et al., 2013).

In addition to $\mathrm{JH}$, biogenic amines, such as melatonin, octopamine, serotonin, and dopamine may affect diurnal activity patterns (reviewed by Bloch et al., 2013). For example, in Tichoplusia ni melatonin levels are highest at night and show rhythmicity in constant darkness but not in constant light (Linn et al., 1995). In Manduca sexta, serotonin levels also show a diurnal pattern, with peak levels when these moths are most active (Kloppenburg et al., 1999). Octopamine has also been indicated as controlling pheromone production, not through activation or release of PBAN, but through inhibition of pheromone production (Rafaeli and Gileadi, 1995; Rafaeli et al., 1999; Hirashima et al., 2001). Octopamine has also been proposed to work as an intermediate messenger during the stimulation of sex pheromone production in H. virescens (Christensen et al., 1991, 1992, 1994), although octopamine has been found to have pheromonotropic activity of PBAN in $H$. armigera (Hirashima et al., 2001). Thus, the exact role of octopamine in pheromone production is not clear yet (Jurenka, 2004).

\section{FACTORS AFFECTING CIRCADIAN RHYTHMS IN MOTHS}

The exogenous factors that affect timing of moth sexual communication are photoperiod and temperature (Sower et al., 1971; Cardé and Roelofs, 1973; Cardé et al., 1975; Baker and Cardé, 1979; Castrovillo and Cardé, 1979; Turgeon and McNeil, 1983; Haynes and Birch, 1984; Delisle and McNeil, 1986), which are the two main Zeitgebers in general. Other exogenous factors that have been investigated to a lesser extent are relative humidity (Royer and McNeil, 1993) and the chemical environment (Anderson et al., 2003, 2007; Silvegren et al., 2005; Sadek et al., 2012).

\section{LIGHT AND LENGTH OF THE SCOTOPHASE}

In moths, a change in daylength can affect timing of female calling, generally to calling later at night when the night gets longer (Delisle and McNeil, 1986; Gerber and Howlader, 1987), although exceptions may occur (e.g., Haynes and Birch, 1986). This may indicate that species in the north are more likely to be active earlier in the night than species closer to the equator. That the length of the scotophase affects the calling rhythm has been shown in Mamestra configurata (Gerber and Howlader, 1987) and in Pseudaletia unipuncta (Delisle and McNeil, 1986): the longer the night, the longer the calling period (Gerber and Howlader, 1987), and in longer nights (12L: 12D), calling started later that in shorter nights (16L: 8D), indicating a relationship between mean onset time of calling and the midpoint of scotophase (Delisle and McNeil, 1986). However, in Platyptilia carduidactyla and $P$. williamsii, a change in daily photoperiodicity did not affect the timing of female calling behavior much (Haynes and Birch, 1986), although in $P$. williamsii females called only in the mid-late scotophase under a light:dark (L:D) regime of 12:12 and 10:14, while they also called in the early morning when kept under 14:10 L:D.

\section{TEMPERATURE}

Temperature affects sexual activity of moths generally such that at lower temperatures females call earlier in the scotophase (see Table 1) (Cardé et al., 1975; Baker and Cardé, 1979). Interestingly, Baker and Cardé (1979) suggest that a decrease in temperature may lift inhibition of calling instead of inducing calling, while higher temperatures may delay expression and thus suppress calling until later in the night. Most likely, the extent to which such shifts occur depends on the possibility of communication interference with closely related species in the same area, as well as the risk of encountering predators (Cardé et al., 1975).

Even though synchronization between female calling and male activity would be most effective, some studies have shown that males respond differently to changes in temperature compared to females, which can result in asynchronous sexual activities in males and females (Baker and Cardé, 1979; Cardé and Baker, 1984; Giebultowicz et al., 1992; Linn, 1997). For example, in Lymantria dispar, females show a shift in pheromone titer to earlier in the day, i.e., from the evening to the early morning when mid-afternoon temperatures are high $\left(33^{\circ} \mathrm{C}\right)$, while male response to pheromone shifts to later in the day, i.e., from 
morning to mid-afternoon at higher temperatures (Giebultowicz et al., 1992).

The mechanism of how temperature can cause a temporal shift in sexual activity has not been investigated in Lepidoptera. In Drosophila melanogaster it was found that isolated brains are not able to synchronize to temperature cycles, so a circadian thermoreceptor is not located in the brain or in the clock neurons, but in the periphery (Sehadova et al., 2009). It seems that some $c r y$-negative neurons are especially sensitive to temperature (Miyasako et al., 2007; Yoshii et al., 2009), which makes those neurons the likely candidates that receive temperature information from the periphery (Peschel and Helfrich-Forster, 2011). Whether such a peripheral circadian thermoreceptor is present in moths remains to be investigated. In $D$. melanogaster two genes have also been identified to influence circadian temperature reception: norpA which encodes for the phospholipase $\mathrm{C}$, and nocte which encodes a large glutamine-rich protein of which the function is unknown (Glaser and Stanewsky, 2005; Sehadova et al., 2009).

\section{RELATIVE HUMIDITY}

A few studies assessed the effect of relative humidity on calling behavior and mating success in moths (Baker and Cardé, 1979; Kanno and Sato, 1979; Royer and McNeil, 1993). In the European corn borer Ostrinia nubilalis fewer females called at low relative humidity compared to high relative humidity when temperature and L:D was held constant and the moths emerged at three different but constant conditions of relative humidity until their sixth night of calling (Royer and McNeil, 1993). Females also began calling later at night, had fewer calling bouts, spent less time calling, and the mating frequency was lower at low RH (Royer and McNeil, 1993). At low relative humidity there may be a higher chance of desiccation, so that the surface area for desiccation can best be kept minimal (Royer and McNeil, 1993). However, other studies did not find an effect of relative humidity on the proportion of females calling or their timing of calling (Baker and Cardé, 1979; Kanno and Sato, 1979).

\section{THE CHEMICAL ENVIRONMENT (PRE-EXPOSURE TO PHEROMONE)}

That the chemical environment influences sexual communication in moths has been shown indirectly, by showing that in overlapping areas of two closely related species the sexual communication channel is more divergent than in non-overlapping areas (e.g., McElfresh and Millar, 1999, 2001; Gries et al., 2001), and directly by showing that females with an altered blend containing less inhibitory compounds attracted heterospecific males (Groot et al., 2006). Thus, reproductive character displacement does seem to occur in moths. However, this is probably a slow process, taking at least a number of generations. Whether the chemical environment can induce short-term plastic responses in moths has hardly been investigated. We found that H. subflexa females contain more of their inhibitory compounds (acetates) when emerged in the odor of the closely related species $H$. virescens, showing for the first time that phenotypic plasticity in moth sex pheromone blends can happen (Groot et al., 2010a). A few studies also showed that the timing of female calling is affected by previous exposure to pheromone, either by advancing the onset time of calling (Palanaswamy and Seabrook, 1978;
Stelinski et al., 2006), delaying the onset time of calling (Noguchi and Tamaki, 1985), prolonging the calling time (Sadek et al., 2012) or not affecting their timing (Dunkelblum et al., 1987; El-Sayed and Suckling, 2005). In some species, females may aggregate upon detecting their own pheromone, most likely to increase their probability of mating success (Birch, 1977). These variable results may be due to experimental conditions or differences in lifestyles (Sadek et al., 2012).

Male response is also affected by previous exposure to pheromone (Anderson et al., 2003, 2007; Silvegren et al., 2005). Brief exposure of $2 \mathrm{~min}$ in the first night caused a significantly quicker and more sensitive response (i.e., to lower doses) the following nights (Anderson et al., 2003, 2007). This effect lasted for at least two nights and suggests that learning is involved in male response (Anderson et al., 2007), or that sensitization of the olfactory neurons occurs. Silvegren et al. (2005) also found that $S$. littoralis males show temporal variation in pheromone response when they were pre-exposed to female pheromone gland extracts a few hours before the expected scotophase, even though they were kept in constant darkness. Such a circadian rhythm was not found in non-pre-exposed males that were kept in constant darkness, suggesting that in the absence of the Zeitgeber light, female pheromone acts as a weak Zeitgeber synchronizing male sensitivity to pheromone with female preference of mating time (Silvegren et al., 2005). Also, the peak of male activity shifted to earlier in the scotophase in pre-exposed males compared to unexposed males (Silvegren et al., 2005). This may be due to male-male competition, as female moths generally mate once a night but every other night, while males mate once a night and every night (e.g., Raulston et al., 1975; Raina and Stadelbacher, 1990; Klepetka and Gould, 1996), so that the operational sex ratio is generally male-biased. The earlier response to sex pheromone can thus be explained as a trial to outcompete other, conspecific males. Whether pre-exposure to heterospecific pheromone affects male response has not been investigated so far. Possibly, this depends on the chance of being attracted to the "wrong" female.

\section{OTHER FACTORS AFFECTING TIMING OF MOTH SEXUAL COMMUNICATION}

Over the past five decades, factors such as age and mating status have been shown to affect daily rhythms in female calling and male response in moths as well.

\section{Age}

In most moth species, females and males start to become sexually active 1-2 days after emergence. In general, pheromone glands contain very low levels of pheromone on the first night after eclosion, which then increases sharply on the second and third night (Pope et al., 1982, 1984; Webster and Cardé, 1982; Heath et al., 1991; Gemeno and Haynes, 2000; Xiang et al., 2010). When females get older, pheromone production generally decreases. For example, in the black cutworm moth Agrotis ipsilon the quantity of the major pheromone component of Z7-12:OAc increased in 1- to 2-day-old females and decreased in 2- to 6-day-old females (Gemeno and Haynes, 2000).

The onset of female calling has been found to become earlier at night when females get older in a number of species 
(e.g., Kanno, 1979; Turgeon and McNeil, 1982; Webster and Cardé, 1982; Howlader and Gerber, 1986a,b; Kou and Chow, 1987; Delisle, 1992; Kamimura and Tatsuki, 1993; Spurgeon et al., 1995). This is probably to increase the chance of getting mated, especially because older females seem to release suboptimal amounts of pheromone (Kanno, 1979; Webster and Cardé, 1982). Thus, female-female competition is likely to affect the timing of female calling as well. However, it is important to note that not all females may initiate calling on the night after emergence (Delisle and Royer, 1994). For example, in a population of 5-day-old females, some females call for the third, second or first night, while other females have not started calling yet (Turgeon and McNeil, 1982; Delisle and McNeil, 1986; Kou and Chow, 1987; Han and Gatehouse, 1991). Therefore, it is probably good to distinguish chronological age (age after emergence) from calling age (age at which females start calling), which likely indicates the day of sexual maturation (Turgeon and McNeil, 1982; Delisle and McNeil, 1986; Gerber and Howlader, 1987).

In contrast to an advance in timing of calling with increasing age, in some species a delay in their period of calling has been found as they get older (Castrovillo and Cardé, 1979; West et al., 1984; Delisle and McNeil, 1986; Schal and Carde, 1986). This may be due to costs that can be associated with shifting calling time if such a shift causes an overlap of timing with another species, causing interspecific communication interference and mating mistakes (Roelofs and Cardé, 1974; Haynes and Birch, 1986), and encountering environmental conditions that reduce mate-finding (Cardé and Baker, 1984; Gemeno and Haynes, 2000).

\section{Mating status}

After female moths are mated, pheromone production and release ceases, at least for the rest of the night, and in a number of species also for the following night (e.g., Raina et al., 1989; Raina and Stadelbacher, 1990; Foster and Roelofs, 1994; Rafaeli and Gileadi, 1995; Ramaswamy et al., 1996; Ahn et al., 2002). Only a few species have been found where the pheromone titer in mated females is reduced to very low amounts for longer periods (e.g., Shorey et al., 1968; Webster and Carde, 1984; Babilis and Mazomenos, 1992). The change in behavior from virgin to mated females has been suggested to be controlled by a male derived peptide, so-called Pheromone Suppressing Peptide (Kingan et al., 1993, 1995; Eliyahu et al., 2003). If male-derived peptides are controlling the change in female behavior, this would thus be better termed an exogenous factor. Virgin females and males have been found to mate earlier in the scotophase than mated individuals, at least in Heliothis virescens (Raina and Stadelbacher, 1990). However, it is unclear whether this is a general trend.

\section{GENETIC BASIS OF VARIATION IN TIMING OF SEXUAL ACTIVITIES}

Even though many genes and factors have been identified that make up the circadian clock in insects and mamals, surprisingly little research has been conducted on which gene(s) underlie variation in timing of sexual activities within and between closely related species. Assessing variation in the identified clock genes is of course very interesting, but it does not give insight in the first genetic changes that have led to differences in timing of activity between specific strains within species or between closely related species. Maybe this is because in Drosophila there are peak activities, but flies are or can be active throughout the day and even at night. In moths, sexual activities really show a daily on-off rhythm; females and males are completely inactive throughout the day and for some hours during the night, and their sexual activities start at specific times at night (see Table 1). This makes moths ideal species to study the genetic basis of withinand between-species variation in these very well defined activity patterns. Below I summarize what is known on the genetic basis of variation in circadian rhythms within and between species.

Variation in timing of sexual activities between species has been investigated by comparing fly species that differ in their timing of mating: e.g., D. melanogaster vs. D. pseudoobscura, the latter mating later (Tauber et al., 2003), D. melangoster vs. D. simulans, also mating slightly out of sync (Ritchie and Kyriacou, 1994; Sakai and Ishida, 2001), flies of the genus Bactrocera, i.e., B. tryoni, mating at dusk, vs. B. neohumeralis, mating at daytime (Tychsen and Fletcher, 1971; Smith, 1979), and two selection lines of B. curcubitae, one line mating at dusk and one line mating at night (Miyatake, 2002).

Sakai and Ishida (2001) tested the mating rhythms of D.melanogaster per ${ }^{01}$ and $\operatorname{tim}^{01}$ null mutant lines that are arrhythmic in their adult emergence and locomoter activity, and found that these lines were also arrhythmic in their mating behavior, indicating the involvement of per and tim in timing of mating activity in D. melanogaster. However, when D. melanogaster per $^{01}$ null lines were transformed with per from D. simulans (sim-transformed) or with per from D. melanogaster (mel-transformed), females did not discriminate between males from the different transformant lines, suggesting that per is not very important in the premating isolation between these two species (Ritchie and Kyriacou, 1994). On the other hand, when Tauber et al. (2003) transformed per from D. pseudoobscura and per from $D$. melanogaster in the per ${ }^{01}$ null mutants, they did rescue the species-specific mating times.

In the two Bactrocera species, An et al. (2002, 2004) found that per had the same cycling phase in the two species and could thus not explain the difference in mating time. Cry also showed a similar diurnal expression patterns in both species, being highest in the morning especially in the antennae, but cry transcript levels were significantly higher in the day-mating B. neohumeralis than in the dusk-mating B. tryoni (An et al., 2004). Miyatake et al. (2002) selected for young (Y) or old (O) reproductive age in $B$. curcubitae, and found that these selection lines also differed in their timing of mating, the Y-line mating at dusk and the O-line mating at night. The fluctuations of per expression levels in these lines reflected their different mating rhythms (Miyatake et al., 2002), again suggesting a role for per in timing of mating. However, since per is located on the sex chromosome and reciprocal hybrids did not differ in their mating rhythm (Miyatake et al., 2002), it is more likely that a trans-acting regulator of per on one of the autosomes is responsible for the variation in mating times.

The above-mentioned studies with their candidate gene approach can only determine whether the already identified clock 
genes may be involved in inter- or intraspecific variation in the circadian rhythm of mating. To identify the exact genetic changes underlying variation in timing of sexual activities, quantitative trait locus (QTL) analysis is needed to identify the genomic location that explains most of the variance, which can also lead to the discovery of new clock components (Tauber and Kyriacou, 2005). In moths, genetic analysis of variation in female calling has been conducted by Monti et al. (1997), who hybridized two closely related Spodoptera species (S. descoinsi and S. latisfascia) and found that females of both reciprocal crosses were intermediate in their calling time. Hence, an autosomal factor is involved in the variation of timing of female calling in these species. We conducted QTL analysis on the variation in timing in the two strains of Spodoptera frugiperda and found that one chromosome, homologous to B.mori chromosome 27, explained most of the variance (Hänniger et al., unpublished results). Interestingly, this chromosome harbors the clock gene vrille, making this our main candidate gene. Even more interestingly, this same chromosome is also the QTL for the pheromone variation between the two strains (Hänniger et al., unpublished results), suggesting a possible genetic interaction or hitchhiking between the two traits.

\section{CONCLUSIONS}

Clearly, different moth species show different daily rhythms in their sexual activities, ranging from female sex pheromone production and female calling to male response and mating. After the vast amount of work in the past five decades to identify the daily activities and circadian rhythms within and between moth species, the current challenge is to determine the underlying mechanism and identify the genetic changes underlying natural variation in these circadian rhythms. Recent studies on behavioral patterns in Drosophila show that circadian behavior in natural populations may be quite different from circadian behavior measured under laboratory conditions (Menegazzi et al., 2012; Vanin et al., 2012), showing the importance of assessing the adaptive significance of rhythmic phenotypes in natural populations. The identified clock regulation and clock genes in Drosophila and Lepidoptera form an excellent basis to assess possible variation in and selection on these genes in moths. With QTL analysis, finescale mapping, mapping the clock genes to these genetic maps, and functional analyses, it will be possible to identify whether inter- and intraspecific variation in circadian timing of sexual activities in moths is due to mutations in these genes themselves, or in trans- or cis-acting regulatory elements in the clockwork. Identifying the exact genetic changes responsible for the speciesor strain-specific timings will be necessary to determine whether and how the evolution of allochronic differentiation coincide or interact with the evolution of sex pheromone composition, which may have led to the enormous diverse group of $\sim 145.000$ moth and butterfly species.

\section{ACKNOWLEDGMENTS}

I thank Sabine Haenniger, Peter Roessingh, Michiel van Wijk and the two reviewers for their valuable comments on earlier versions of this manuscript. My research is funded by IBED-UvA, the Max Planck Gesellschaft, NSF (grant nr IOS-1052238) and NWO-ALW (grant nr. 822.01.012).

\section{REFERENCES}

Acharya, L., and McNeil, J. N. (1998). Predation risk and mating behavior: the responses of moths to bat-like ultrasound. Behav. Ecol. 9, 552-558. doi: 10.1093/beheco/9.6.552

Ahn, S. J., Choi, M. Y., and Boo, K. S. (2002). Mating effect on sex pheromone production of the Oriental tobacco budworm, Helicoverpa assulta. J. Asia-Pacif. Entomol. 5, 43-48. doi: 10.1016/S1226-8615(08)60131-4

Allison, J. D., and Carde, R. T. (2008). Male pheromone blend preference function measured in choice and no-choice wind tunnel trials with almond moths, Cadra cautella. Anim. Behav. 75, 259-266. doi: 10.1016/j.anbehav.2007.04.033

An, X., Tebo, M., Song, S., Frommer, M., and Raphael, K. A. (2004). The cryptochrome (cry) gene and a mating isolation mechanism in tephritid fruit flies. Genetics 168, 2025-2036. doi: 10.1534/genetics.104.028399

An, X., Wilkes, K., Bastian, Y., Morrow, J. L., Frommer, M., and Raphael, K. A. (2002). The period gene in two species of tephritid fruit fly differentiated by mating behaviour. Insect Mol. Biol. 11, 419-430. doi: 10.1046/j.13652583.2002.00351.x

Anderson, J., Borg-Karlson, A. K., Vongvanich, N., and Wiklund, C. (2007). Male sex pheromone release and female mate choice in a butterfly. J. Exp. Biol. 210, 964-970. doi: 10.1242/jeb.02726

Anderson, P., Sadek, M. M., and Hansson, B. S. (2003). Pre-exposure modulates attraction to sex pheromone in a moth. Chem. Senses 28, 285-291. doi: 10.1093/chemse/28.4.285

Anton, S., and Gadenne, C. (1999). Effect of juvenile hormone on the central nervous processing of sex pheromone in an insect. Proc. Natl. Acad. Sci. U.S.A. 96, 5764-5767. doi: 10.1073/pnas.96.10.5764

Arima, R., Takahara, K., Kadoshima, T., Numazaki, F., Ando, T., Uchiyama, M., et al. (1991). Hormonal regulation of pheromone biosynthesis in the silkworm moth, Bombyx mori (Lepidoptera, Bombycidae). Appl. Entomol. Zool. 26, 137-147.

Babilis, N. A., and Mazomenos, B. E. (1992). Pheromone production in Sesamia nonagrioides - Diel periodicity and effect of age and mating. J. Insect Physiol. 38, 561-564. doi: 10.1016/0022-1910(92)90106-N

Baker, T. C., and Carde, R. T. (1978). Disruption of gypsy moth (Lepidoptera, Lymantriidae) male sex pheromone behavior by high frequency sound. Environ. Entomol. 7, 45-52.

Baker, T. C., and Cardé, R. T. (1979). Endogenous and exogenous factors affecting periodicities of female calling and male sex pheromone response in Grapholitha molesta (Busck). J. Insect Physiol. 25, 943-950. doi: 10.1016/00221910(79)90107-0

Bazinet, A. L., Cummings, M. P., Mitter, K. T., and Mitter, C. W. (2013). Can RNASeq resolve the rapid radiation of advanced moths and butterflies (Hexapoda: Lepidoptera: Apoditrysia)? An exploratory study. PLOS ONE 8:e82615. doi: 10.1371/journal.pone.0082615

Birch, M. C. (1977). Responses of both sexes of Trichoplusia ni (Lepidoptera, Noctuidae) to virgin females and to synthetic pheromone Ecol. Entomol. 2, 99-104.

Bjostad, L. B., Gaston, L. K., and Shorey, H. H. (1980). Temporal pattern of sex pheromone release by female Trichoplusia ni. J. Insect Physiol. 26, 493-498. doi: 10.1016/0022-1910(80)90122-5

Bjostad, L. B., Wolf, W. A., and Roelofs, W. L. (1987). "Pheromone biosynthesis in lepidopterans: desaturation and chain shortening," in Pheromone Biochemistry, eds G. D. Prestwich and G. J. Blomquist (Orlando, FL: Academic Press, Inc.), 77-117

Bloch, G., Hazan, E., and Rafaeli, A. (2013). Circadian rhythms and endocrine functions in adult insects. J. Insect Physiol. 59, 56-69. doi: 10.1016/j.jinsphys.2012.10.012

Blomquist, G. J., and Vogt, R. G. (2003). Insect Pheromone Biochemistry and Molecular Biology. London: Elsevier Academic.

Boo, K. S., Park, K. C., Hall, D. R., Cork, A., Berg, B. G., and Mustaparta, H. (1995) (Z)-9-Tetradecenal - a potent inhibitor of pheromone-mediated communication in the Oriental tobacco budworm, Helicoverpa assulta. J. Comp. Physiol. A. 177, 695-699.

Cardé, R. T., and Baker, T. C. (1984). "Sexual communication with pheromones," in Chemical Ecology of Insects, eds W. J. Bell and R. T. Cardé ( London: Chapman and Hall), 355-383

Cardé, R. T., Cardé, A. M., Hill, A. S., and Roelofs, W. L. (1977). Sex pheromone specificity as a reproductive isolating mechanism among sibling species Archips argyrospilus and A. mortuanus and other sympatric tortricine 
moths (Lepidoptera, Tortricidae). J. Chem. Ecol. 3, 71-84. doi: 10.1007/BF00 988135

Cardé, R. T., Comeau, A., Baker, T. C., and Roelofs, W. L. (1975). Moth mating periodicity - temperature regulates circadian gate. Experientia 31, 46-48. doi: 10.1007/BF01924672

Cardé, R. T., Doane, C. C., and Roelofs, W. L. (1974). Diel periodicity of male sex pheromone response and female attractiveness in gypsy moth (Lepidoptera, Lymantriidae). Can. Entomol. 106, 479-484. doi: 10.4039/Ent106479-5

Cardé, R. T., and Roelofs, W. L. (1973). Temperature modification of male sex pheromone response and factors affecting female calling in Holomelina immaculata (Lepidoptera, Arctiidae). Can. Entomol. 105, 1505-1512. doi: 10.4039/Ent1051505-12

Castrovillo, P. J., and Cardé, R. T. (1979). Environmental regulation of female calling and male pheromone response periodicities in the codling moth (Laspeyresia pomonella) J. Insect Physiol. 25, 659-667. doi: 10.1016/00221910(79)90116-1

Chang, D. C., McWatters, H. G., Williams, J. A., Gotter, A. L., Levine, J. D., and Reppert, S. M. (2003). Constructing a feedback loop with circadian clock molecules from the silkmoth, Antheraea pernyi. J. Biol. Chem. 278, 38149-38158. doi: 10.1074/jbc.M306937200

Charlton, R. E., and Cardé, R. T. (1982). Rate and diel periodicity of pheromone emission from female gypsy moths (Lymantria dispar) determined with a glass adsorption collection system. J. Insect Physiol. 28, 423-430. doi: 10.1016/00221910(82)90069-5

Choi, M. Y., Tatsuki, S., and Boo, K. S. (1998). Regulation of sex pheromone biosynthesis in the oriental tobacco budworm, Helicoverpa assulta (Lepidoptera: Noctuidae). J. Insect Physiol. 44, 653-658. doi: 10.1016/S0022-1910(98)00029-8

Christensen, T. A., Itagaki, H., Teal, P. E. A., Jasensky, R. D., Tumlinson, J. H., and Hildebrand, J. G. (1991). Innervation and neural regulation of the sex pheromone gland in female Heliothis moths. Proc. Natl. Acad. Sci. U.S.A. 88, 4971-4975. doi: 10.1073/pnas.88.11.4971

Christensen, T. A., Lashbrook, J. M., and Hildebrand, J. G. (1994). Neural activation of the sex pheromone gland in the moth Manduca sexta - Realtime measurement of pheromone release. Physiol. Entomol. 19, 265-270. doi: 10.1111/j.1365-3032.1994.tb01051.x

Christensen, T. A., Lehman, H. K., Teal, P. E. A., Itagaki, H., Tumlinson, J. H., and Hildebrand, J. G. (1992). Diel changes in the presence and physiological actions of octopamine in the female sex pheromone glands of heliothine moths. Insect Biochem. Mol. Biol. 22, 841-849. doi: 10.1016/0965-1748(92)90110-Z

Coffelt, J. A., Sower, L. L., and Vick, K. W. (1978). Quantitative analysis of identified compounds of pheromone gland rinses of Plodia interpunctella and Ephestia cautella at different times of day. Environ. Entomol. 7, 502-505.

Collins, R. D., and Cardé, R. T. (1985). Variation in and heritability of aspects of pheromone production in the pink bollworm moth, Pectinophora gossypiella (Lepidoptera, Gelechiidae). Ann. Entomol. Soc. Am. 78, 229-234.

Conner, W. E., and Corcoran, A. J. (2012). Sound strategies: the 65-millionyear-old battle between bats and insects. Annu. Rev. Entomol. 57, 21-39. doi: 10.1146/annurev-ento-121510-133537

Corcoran, A. J., and Conner, W. E. (2012). Sonar jamming in the field: effectiveness and behavior of a unique prey defense. J. Exp. Biol. 215, 4278-4287. doi: 10.1242/jeb.076943

Cossé, A. A., Campbell, M. G., Glover, T. J., Linn, C. E., Todd, J. L., Baker, T. C., et al. (1995). Pheromone behavioral responses in unusual male European corn borer hybrid progeny not correlated to electrophysiological phenotypes of their pheromone-specific antennal neurons. Experientia 51, 809-816. doi: 10.1007/BF01922435

Coyne, J. A., and Orr, H. A. (2004). Speciation. (Sunderland, MA: Sinauer Associates, Inc.)

Cusson, M., and McNeil, J. N. (1989). Involvement of juvenile hormone in the regulation of pheromone release activities in a moth. Science 243, 210-211. doi: 10.1126/science.243.4888.210

Cusson, M., Tobe, S. S., and McNeil, J. N. (1994). Juvenile hormones - their role in the regulation of the pheromonal communication-system of the armyworm moth, Pseudaletia-unipuncta. Arch. Insect Biochem. Physiol. 25, 329-345. doi: 10.1002/arch.940250408

Cyran, S. A., Buchsbaum, A. M., Reddy, K. L., Lin, M.-C., Glossop, N. R. J., Hardin, P. E., et al. (2003). vrille, Pdp1, and dClock form a second feedback loop in the Drosophila circadian clock. Cell 112, 329-341. doi: 10.1016/S00928674(03)00074-6
Delisle, J. (1992). Age-related changes in the calling behavior and the attractiveness of obliquebanded leafroller virgin females, Choristoneura rosaceana, under different constant and fluctuating temperature conditions. Entomol. Exp. Appl. 63, 55-62. doi: 10.1111/j.1570-7458.1992.tb02419.x

Delisle, J., and McNeil, J. N. (1986). The effect of photoperiod on the calling behavior of virgin females of the true armyworm, Pseudaletia unipuncta (Haw) (Lepidoptera, Noctuidae). J. Insect Physiol. 32, 199-206. doi: 10.1016/00221910(86)90059-4

Delisle, J., and McNeil, J. N. (1987). Calling behavior and pheromone titer of the true armyworm pseudaletia-unipuncta (Haw) (Lepidoptera, Noctuidae) under different temperature and photoperiodic conditions. J. Insect Physiol. 33, 315-324. doi: 10.1016/0022-1910(87)90119-3

Delisle, J., Picimbon, J. F., and Simard, J. (1999). Physiological control of pheromone production in Choristoneura fumiferana and C.rosaceana. Arch. Insect Biochem. Physiol. 42, 253-265. doi: 10.1002/(SICI)1520-6327(199912)42: 4<253::AID-ARCH4>3.0.CO;2-S

Delisle, J., and Royer, L. (1994). Changes in pheromone titer of oblique-banded leafroller Choristoneura rosaceana virgin females as a function of time of day, age and temperature. J. Chem. Ecol. 20, 45-69. doi: 10.1007/BF02065990

Devries, P. J., Austin, G. T., and Martin, N. H. (2008). Diel activity and reproductive isolation in a diverse assemblage of Neotropical skippers (Lepidoptera: Hesperiidae). Biol. J. Linn. Soc. 94, 723-736. doi: 10.1111/j.10958312.2008.01037.x

Dong, S. L., and Du, J. W. (2001). Diel rhythms of calling behavior and sex pheromone production of beet armyworm Spodoptera exigua (Lepidoptera, Noctuidae). Entomol. Sinica 8, 89-96. doi: 10.1111/j.1744-7917.2001.tb00439.x

Dunkelblum, E., Kehat, M., Harel, M., and Gordon, D. (1987). Sexual behavior and pheromone titer of the Spodoptera littoralis female moth. Entomol. Exp. Appl. 44, 241-247. doi: 10.1111/j.1570-7458.1987.tb00551.x

Edery, I. (2000). Circadian rhythms in a nutshell. Physiol. Genomics 3, 59-74.

Eliyahu, D., Nagalakshmi, V., Applebaum, S. W., Kubli, E., Choffat, Y., and Rafaeli, A. (2003). Inhibition of pheromone biosynthesis in Helicoverpa armigera by pheromonostatic peptides. J. Insect Physiol. 49, 569-574. doi: 10.1016/S00221910(03)00028-3

El-Sayed, A. M. (2014). The Pherobase: Database of Insect Pheromones and Semiochemicals. Available online at: http://www.pherobase.com

El-Sayed, A. M., and Suckling, D. M. (2005). Behavioural observations of mating disruption in three lepidopteran pests. Behaviour 142, 717-729. doi: $10.1163 / 1568539054729114$

Eltahlawy, H., Buckner, J. S., and Foster, S. P. (2007). Evidence for two-step regulation of pheromone biosynthesis by the pheromone biosynthesis-activating neuropeptide in the moth Heliothis virescens. Arch. Insect Biochem. Physiol. 64, 120-130. doi: 10.1002/arch.20164

Emery, P., So, W. V., Kaneko, M., Hall, J. C., and Rosbash, M. (1998). CRY, a Drosophila clock and light-regulated cryptochrome, is a major contributor to circadian rhythm resetting and photosensitivity. Cell 95, 669-679. doi: 10.1016/S0092-8674(00)81637-2

Fan, Y. L., Rafaeli, A., Gileadi, C., and Applebaum, S. W. (1999). Juvenile hormone induction of pheromone gland PBAN-responsiveness in Helicoverpa armigera females. Insect Biochem. Mol. Biol. 29, 635-641. doi: 10.1016/S09651748(99)00041-7

Fatzinger, C. W. (1973). Circadian rhythmicity of sex pheromone release by Doryctria abietella (Lepidoptera: Pyralidae (Phycitinae) and the effect of a diel light cycle on its precopulatory behavior. Ann. Entomol. Soc. Am. 66, 1147-1153.

Fergus, D. J., deCarvalho, T. N., and Shaw, K. L. (2011). Genetically regulated temporal variation of novel courtship elements in the Hawaiian cricket genus Laupala. Behav. Genet. 41, 607-614. doi: 10.1007/s10519-010-9397-2

Fonagy, A., Yokoyama, N., and Matsumoto, S. (2001). Physiological status and change of cytoplasmic lipid droplets in the pheromone-producing cells of the silkmoth, Bombyx mori (Lepidoptera, Bombycidae). Arthropod Struct. Dev. 30, 113-123. doi: 10.1016/S1467-8039(01)00027-5

Foster, S. (2009). Sugar feeding via trehalose haemolymph concentration affects sex pheromone production in mated Heliothis virescens moths. J. Exp. Biol. 212, 2789-2794. doi: 10.1242/jeb.030676

Foster, S. P. (2000). Periodicity of sex pheromone biosynthesis, release and degradation in the lightbrown apple moth, Epiphyas postvittana (Walker). Arch. Insect Biochem. Physiol. 43, 125-136. doi: 10.1002/(SICI)15206327(200003)43:3\%3C125::AID-ARCH4\%3E3.0.CO;2-M 
Foster, S. P. (2004). The effects of topical application of various fatty acids on pheromone and glandular lipid blosynthesis in the moth Heliothis virescens. Insect Biochem. Mol. Biol. 34, 467-475. doi: 10.1016/j.ibmb.2004.02.007

Foster, S. P., and Anderson, K. G. (2012). Synthetic rates of key stored fatty acids in the biosynthesis of sex pheromone in the moth Heliothis virescens. Insect Biochem. Mol. Biol. 42, 865-872. doi: 10.1016/j.ibmb.2012.08.004

Foster, S. P., and Roelofs, W. L. (1994). Regulation of pheromone production in virgin and mated females of 2 tortricid moths. Arch. Insect Biochem. Physiol. 25, 271-285. doi: 10.1002/arch.940250404

Froy, O., Gotter, A. L., Casselman, A. L., and Reppert, S. M. (2003). Illuminating the circadian clock in monarch butterfly migration. Science 300, 1303-1305. doi: 10.1126/science. 1084874

Gadenne, C., Renou, M., and Sreng, L. (1993). Hormonal control of pheromone responsiveness in the male back cutworm Agrotis ipsilon. Experientia 49, 721-724. doi: 10.1007/BF01923960

Gemeno, C., and Haynes, K. F. (2000). Periodical and age-related variation in chemical communication system of black cutworm moth, Agrotis ipsilon. J. Chem. Ecol. 26, 329-342. doi: 10.1023/A:1005468203045

Gerber, G. H., and Howlader, M. A. (1987). The effect of photoperiod and temperature on calling behavior and egg development of the bertha armyworm, Mamestra configurata (Lepidoptera, Noctuidae). J. Insect Physiol. 33, 429-436. doi: 10.1016/0022-1910(87)90022-9

Giebultowicz, J. M. (2000). Molecular mechanism and cellular distribution of insect circadian clocks. Annu. Rev. Entomol. 45, 769-793. doi: 10.1146/annurev.ento.45.1.769

Giebultowicz, J. M. (2001). Peripheral clocks and their role in circadian timing: insights from insects. Philos. Trans. R. Soc. Lond. B Biol. Sci. 356, 1791-1799. doi: $10.1098 /$ rstb.2001.0960

Giebultowicz, J. M., Ridgway, R. L., and Imberski, R. B. (1990). Physiological basis for sterilizing effects of constant light in Lymantria dispar. Physiol. Entomol. 15, 149-156. doi: 10.1111/j.1365-3032.1990.tb00502.x

Giebultowicz, J. M., Riemann, J. G., Raina, A. K., and Ridgway, R. L. (1989). Circadian system controlling release of sperm in the insect testes. Science 245, 1098-1100. doi: 10.1126/science.245.4922.1098

Giebultowicz, J. M., Webb, R. E., Raina, A. K., and Ridgway, R. L. (1992). Effects of temperature and age on daily changes in pheromone titer in laboratoryreared and wild gypsy moth (Lepidoptera, Lymantriidae). Environ. Entomol. 21, 822-826.

Glaser, F. T., and Stanewsky, R. (2005). Temperature synchronization of the Drosophila circadian clock. Curr. Biol. 15, 1352-1363. doi: 10.1016/j.cub.2005. 06.056

Gorsuch, C. S., Karandinos, M. G., and Koval, C. F. (1975). Daily rhythms of Synanthedon pictipes (Lepidoptera, Aegeriida) female calling behavior in Wisconsin - temperature effects. Entomol. Exp. Appl. 18, 367-376. doi: 10.1111/ j.1570-7458.1975.tb00409.x

Gotter, A. L., Levine, J. D., and Reppert, S. M. (1999). Sex-linked period genes in the silkmoth, Antheraea pernyi: implications for circadian clock regulation and the evolution of sex chromosomes. Neuron 24, 953-965. doi: 10.1016/S08966273(00)81042-9

Gould, F., Groot, A. T., Vasquez, G. M., and Schal, C. (2009). "Sexual communication in Lepidoptera: a need for wedding genetics, biochemistry, and molecular biology," in Molecular Biology and Genetics of the Lepidoptera, eds M. R. Goldsmith and F. Marec (New York, NY: Taylor \& Francis), 169-194.

Greenfield, M. D. (1981). Moth sex pheromones - an evolutionary perspective. Fla. Entomol. 64, 4-17. doi: 10.2307/3494597

Greenfield, M. D., and Karandinos, M. G. (1979). Resource partitioning of the sex communication channel in clearwing moths (Lepidoptera, Sesiidae) of Wisconsin. Ecol. Monogr. 49, 403-426. doi: 10.2307/1942470

Gries, G., Schaefer, P. W., Gries, R., Liska, J., and Gotoh, T. (2001). Reproductive character displacement in Lymantria monacha from northern Japan? J. Chem. Ecol. 27, 1163-1176. doi: 10.1023/A:1010316029165

Groot, A. T., Classen, A., Staudacher, H., Schal, C., and Heckel, D. G. (2010a). Phenotypic plasticity in sexual communication signal of a noctuid moth. J. Evol. Biol. 23, 2731-2738. doi: 10.1111/j.1420-9101.2010.02124.x

Groot, A. T., Estock, M. L., Horovitz, J. L., Hamilton, J., Santangelo, R. G., Schal, C., et al. (2009). QTL analysis of sex pheromone blend differences between two closely related moths: insights into divergence in biosynthetic pathways. Insect Biochem. Mol. Biol. 39, 568-577. doi: 10.1016/j.ibmb.2009.05.002
Groot, A. T., Horovitz, J. L., Hamilton, J., Santangelo, R. G., Schal, C., and Gould, F. (2006). Experimental evidence for interspecific directional selection on moth pheromone communication. Proc. Natl. Acad. Sci. U.S.A. 103, 5858-5863. doi: 10.1073/pnas.0508609103

Groot, A. T., Marr, M., Heckel, D. G., and Schofl, G. (2010b). The roles and interactions of reproductive isolation mechanisms in fall armyworm (Lepidoptera: Noctuidae) host strains. Ecol. Entomol. 35, 105-118. doi: 10.1111/j.13652311.2009.01138.x

Groot, A. T., Marr, M., Schofl, G., Lorenz, S., Svatos, A., and Heckel, D. G. (2008). Host strain specific sex pheromone variation in Spodoptera frugiperda. Front. Zool. 5:20. doi: 10.1186/1742-9994-5-20

Groot, A. T., Schofl, G., Inglis, O., Donnerhacke, S., Classen, A., Schmalz, A., et al. (2014). Within-population variability in a moth sex pheromone blend: genetic basis and behavioral consequences. Proc. Biol. Sci. 281:20133054. doi: 10.1098/ rspb.2013.3054

Gvakharia, B. O., Kilgore, J. A., Bebas, P., and Giebultowicz, J. M. (2000). Temporal and spatial expression of the period gene in the reproductive system of the codling moth. J. Biol. Rhythms 15, 4-12. doi: 10.1177/074873040001500102

Hall, J. C. (2003). Genetics and molecular biology of rhythms in Drosophila and other insects. Adv. Genet. 48, 1-280. doi: 10.1016/S0065-2660(03) 48000-0

Han, E. N., and Gatehouse, A. G. (1991). The effect of adult feeding on female pre-calling period and ovarian development in a migratory moth, the oriental armyworm Mythimna separata (Lepidoptera, Noctuidae). Bull. Entomol. Res. 81, 395-400. doi: 10.1017/S0007485300031953

Hardin, P. E. (2005). The circadian timekeeping system of Drosophila. Curr. Biol. 15, R714-R722. doi: 10.1016/j.cub.2005.08.019

Hardin, P. E. (2011). "Molecular genetic analysis of circadian timekeeping in Drosophila," in Genetics of Circadian Rhythms, ed S. Brody (San Diego, CA: Elsevier Academic Press Inc.), 141-173. doi: 10.1016/B978-0-12-3876904.00005-2

Haynes, K. F., and Birch, M. C. (1984). Mate location and courtship behaviors of the artichoke plume moth, Platyptilia carduidactyla (Lepidoptera, Pterophoridae). Environ. Entomol. 13, 399-408.

Haynes, K. F., and Birch, M. C. (1986). Temporal reproductive isolation between 2 species of plume moths (Lepidoptera, Pterophoridae). Ann. Entomol. Soc. Am. 79, 210-215.

Heath, R. R., McLaughlin, J. R., Proshold, F., and Teal, P. E. A. (1991). Periodicity of female sex pheromone titer and release in Heliothis subflexa and H. virescens (Lepidoptera, Noctuidae). Ann. Entomol. Soc. Am. 84, 182-189.

Helfrich-Forster, C. (1998). Robust circadian rhythmicity of Drosophila melanogaster requires the presence of lateral neurons: a brain-behavioral study of disconnected mutants. J. Comp. Physiol. A 182, 435-453. doi: $10.1007 / \mathrm{s} 003590050192$

Helfrich-Forster, C. (2004). The circadian clock in the brain: a structural and functional comparison between mammals and insects. J. Comp. Physiol. A 190, 601-613. doi: 10.1007/s00359-004-0527-2

Helfrich-Forster, C., Winter, C., Hofbauer, A., Hall, J. C., and Stanewsky, R. (2001). The circadian clock of fruit flies is blind after elimination of all known photoreceptors. Neuron 30, 249-261. doi: 10.1016/S0896-6273(01)00277-X

Hermann, C., Saccon, R., Senthilan, P. R., Domnik, L., Dircksen, H., Yoshii, T., et al. (2013). The circadian clock network in the brain of different Drosophila species. J. Comp. Neurol. 521, 367-388. doi: 10.1002/cne.23178

Hirashima, A., Eiraku, T., Watanabe, Y., Kuwano, E., Taniguchi, E., and Morifusa, E. (2001). Identification of novel inhibitors of calling and in vitro $\left[{ }^{14} \mathrm{C}\right]$ acetate incorporation by pheromone glands of Plodia interpunctella. Pest Manage. Sci. 57, 713-720. doi: 10.1002/ps.345

Howlader, M. A., and Gerber, G. H. (1986a). Calling behavior of the Bertha armyworm, Mamestra configurata (Lepidopteaa, Noctuidae). Can. Entomol. 118, 735-743.

Howlader, M. A., and Gerber, G. H. (1986b). Effects of age, egg development, and mating on calling behavior of the Bertha army worm, Mamestra configurata Walker (Lepidoptera, Noctuidae). Can. Entomol. 118, 1221-1230.

Hunt, R. E., and Haynes, K. F. (1990). Periodicity in the quantity and blend ratios of pheromone components in glands and volatile emissions of mutant and normal cabbage looper moths, Trichoplusia ni. J. Insect Physiol. 36, 769-774. doi: 10.1016/0022-1910(90)90050-P

Iglesias, F., Jacquin-Joly, E., Marco, M. P., Camps, F., and Fabrias, G. (1999). Temporal distribution of PBAN-like immunoreactivity in the hemolymph of 
Mamestra brassicae females in relation to sex pheromone production and calling behavior. Arch. Insect Biochem. Physiol. 40, 80-87.

Iglesias, F., Marco, P., Francois, M. C., Camps, F., Fabrias, G., and Jacquin-Joly, E. (2002). A new member of the PBAN family in Spodoptera littoralis: molecular cloning and immunovisualisation in scotophase hemolymph. Insect Biochem. Mol. Biol. 32, 901-908. doi: 10.1016/S0965-1748(01)00179-5

Itagaki, H., and Conner, W. E. (1988). Calling behavior of Manduca sexta (L.) (Lepidoptera, Sphingidae) with notes on the morphology of the sex pheromone gland. Ann. Entomol. Soc. Am. 81, 798-807.

Ivanchenko, M., Stanewsky, R., and Giebultowicz, J. M. (2001). Circadian photoreception in Drosophila: functions of cryptochrome in peripheral and central clocks. J. Biol. Rhythms 16, 205-215. doi: 10.1177/074873040101600303

Jurenka, R. (2003). "Biochemistry of female moth sex pheromones," in Insect Pheromone Biochemistry and Molecular Biology, eds G. J. Blomquist and R. Vogt (London: Elsevier Academic Press), 53-80. doi: 10.1016/B978-0121071516/50005-0

Jurenka, R. (2004). "Insect pheromone biosynthesis," in Chemistry of Pheromones and Other Semiochemicals, I, ed S. Schulz (Berlin; Heidelberg: Springer-Verlag), 97-131

Jurenka, R. A., Haynes, K. F., Adlof, R. O., Bengtsson, M., and Roelofs, W. L. (1994). Sex-pheromone component ratio in the cabbage-looper moth altered by a mutation affecting the fatty-acid chain-shortening reactions in the pheromone biosynthetic-pathway. Insect Biochem. Mol. Biol. 24, 373-381. doi: 10.1016/0965-1748(94)90030-2

Jurenka, R. A., and Rafaeli, A. (2011). Regulatory role of PBAN in sex pheromone biosynthesis of heliothine moths. Front. Endocrinol. 2:46. doi: 10.3389/fendo.2011.00046

Kamimura, M., and Tatsuki, S. (1993). Diel rhythms of calling behavior and pheromone production of oriental tobacco budworm moth, Helicoverpa assulta (Lepidoptera, Noctuidae). J. Chem. Ecol. 19, 2953-2963. doi: 10.1007/BF00980595

Kanno, H. (1979). Effects of age on calling behavior of the rice stem borer, Chilo suppressalis (Walker) (Lepidoptera, Pyralidae). Bull. Entomol. Res. 69, 331-335. doi: $10.1017 /$ S0007485300017806

Kanno, H., and Sato, A. (1979). Mating behavior of the rice stem borer moth, Chilo suppressalis Walker (Lepidoptera, Pyralidae). 2. Effects of temperature and relative humidity on mating activity. Appl. Entomol. Zool. 14, 419-427.

Karpati, Z., Molnar, B., and Szocs, G. (2007). Pheromone titer and mating frequency of E- and Z-strains of the European corn borer, Ostrinia nubilalis: fluctuation during scotophase and age dependence. Acta Phytopathol. Entomol. Hung. 42, 331-341. doi: 10.1556/APhyt.42.2007.2.15

Kawasaki, K. (1986). Activity rhythms and behavior of adult Spodoptera litura $\mathrm{F}$ (Lepidoptera, Noctuidae) at night - factors determining male attraction time by females Appl. Entomol. Zool. 21, 493-499.

Kingan, T. G., Bodnar, W. M., Raina, A. K., Shabanowitz, J., and Hunt, D. F. (1995). The loss of female sex pheromone after mating in the corn earworm moth Helicoverpa zea - Identification of a male pheromonostatic peptide. Proc. Natl. Acad. Sci. U.S.A. 92, 5082-5086. doi: 10.1073/pnas.92.11.5082

Kingan, T. G., Thomaslaemont, P. A., and Raina, A. K. (1993). Male accessory gland factors elicit change from virgin to mated behavior in the female corn earworm moth Helicoverpa zea. J. Exp. Biol. 183, 61-76.

Klepetka, B., and Gould, F. (1996). Effects of age and size on mating in Heliothis virescens (Lepidoptera: Noctuidae): implications for resistance management. Environ. Entomol. 25, 993-1001.

Kloppenburg, P., Ferns, D., and Mercer, A. R. (1999). Serotonin enhances central olfactory neuron responses to female sex pheromone in the male sphinx moth Manduca sexta. J. Neurosci. 19, 8172-8181.

Konno, Y. (1986). Time-lag between sex pheromone content and the calling behavior in the yellow peach moth, Conogethes punctiferalis (Guenee) (Lepidoptera, Pyralidae). Appl. Entomol. Zool. 21, 622-624.

Konopka, R. J., and Benzer, S. (1971). Clock mutants of Drosophila melanogaster. Proc. Natl. Acad. Sci. U.S.A. 68, 2112-2116. doi: 10.1073/pnas.68.9.2112

Konopka, R. J., Pittendrigh, C., and Orr, D. (1989). Reciprocal behavior associatied with altered homeostasis and photosensitivity of Drosophila clock mutants. J. Neurogenet. 6, 1-10. doi: 10.3109/01677068909107096

Kotwica-Rolinska, J., Gvakharia, B. O., Kedzierska, U., Giebultowicz, J. M., and Bebas, P. (2013). Effects of period RNAi on V-ATPase expression and rhythmic $\mathrm{pH}$ changes in the vas deferens of Spodoptera littoralis (Lepidoptera: Noctuidae). Insect Biochem. Mol. Biol. 43, 522-532. doi: 10.1016/j.ibmb.2013.03.002
Kou, R., and Chow, Y.-S. (1987). Calling behavior of the cotton bollworm, Heliothis armigera (Lepidoptera: Noctuidae). Ann. Entomol. Soc. Am. 80, 490-493.

Kyriacou, C. P., Peixoto, A. A., Sandrelli, F., Costa, R., and Tauber, E. (2008). Clines in clock genes: fine-tuning circadian rhythms to the environment. Trends Genet. 24, 124-132. doi: 10.1016/j.tig.2007.12.003

Levine, J. D., Sauman, I., Imbalzano, M., Reppert, S. M., and Jackson, F. R. (1995). Period protein from the giant silkmoth Antheraea pernyi functions as a circadian clock element in Drosophila melanogaster. Neuron 15, 147-157. doi: 10.1016/0896-6273(95)90072-1

Lima, E. R., and McNeil, J. N. (2009). Female sex pheromones in the host races and hybrids of the fall armyworm, Spodoptera frugiperda (Lepidoptera: Noctuidae). Chemoecology 19, 29-36. doi: 10.1007/s00049-009-0005-y

Linn, C. E. (1997). "Neuroendocrine factors in the photoperiodic control of male moth responsiveness to sex pheromone," in Insect Pheromone Research: New Directions, eds R. T. Carde and A. K. Minks (New York, NY: Chapman \& Hall), 194-209

Linn, C. E., Campbell, M. G., Poole, K. R., Wu, W. Q., and Roelofs, W. L. (1996). Effects of photoperiod on the circadian timing of pheromone response in male Trichoplusia ni: relationship to the modulatory action of octopamine. J. Insect Physiol. 42, 881-891. doi: 10.1016/0022-1910(96)00034-0

Linn, C. E., Poole, K. R., Wu, W. Q., and Roelofs, W. L. (1995). Circadian changes in melatonin in the nervous system and hemolymph of the cabbage loooper moth, Trichoplusia ni. J. Comp. Physiol. A. 176, 761-771.

Linn, C. E., Young, M. S., Gendle, M., Glover, T. J., and Roelofs, W. L. (1997). Sex pheromone blend discrimination in two races and hybrids of the European corn borer moth, Ostrinia nubilalis. Physiol. Entomol. 22, 212-223. doi: 10.1111/j.1365-3032.1997.tb01161.x

Löfstedt, C. (1993). Moth pheromone genetics and evolution. Philos. Trans. R. Soc. Lond. B 340, 167-177. doi: 10.1098/rstb.1993.0055

Löfstedt, C., Vanderpers, J. N. C., Lofqvist, J., Lanne, B. S., Appelgren, M., Bergstrom, G., et al. (1982). Sex pheromone components of the turnip moth, Agrotis segetum Schiff (Lepidoptera, Noctuidae) - Chemical identification, electrophysiological evaluation and behavioral activity. J. Chem. Ecol. 8, 1305-1321. doi: 10.1007/BF00987764

Löfstedt, C., Vickers, N. J., and Baker, T. C. (1990). Courtship, pheromone titer and determination of the male mating success in the Oriental fruit moth, Grapholita molesta (Lepidoptera, Tortricidae). Entomol. Gen. 15, 121-125. doi: 10.1127/entom.gen/15/1990/121

Martinez, T., and Camps, F. (1988). Stimulation of sex pheromone production by head extract in Spodoptera littoralis at different times of the photoperiod. Arch. Insect Biochem. Physiol. 9, 211-220. doi: 10.1002/arch. 940090305

Matsumoto, S., Fonagy, A., Yamamoto, M., Wang, F., Yokoyama, N., Esumi, Y., et al. (2002). Chemical characterization of cytoplasmic lipid droplets in the pheromone-producing cells of the silkmoth, Bombyx mori. Insect Biochem. Mol. Biol. 32, 1447-1455. doi: 10.1016/S0965-1748(02)00065-6

Matsumoto, S., Ohnishi, A., Lee, J. M., and Hull, J. J. (2010). Unraveling the pheromone biosynthesis activating neuropeptide (PBAN) signal transduction cascade that regulates sex pheromone production. Vitam. Horm. 83, 425-445. doi: $10.1016 / \mathrm{S} 0083-6729(10) 83018-3$

Mazor, M., and Dunkelblum, E. (2005). Circadian rhythms of sexual behavior and pheromone titers of two closely related moth species Autographa gamma and Cornutiplusia circumflexa. J. Chem. Ecol. 31, 2153-2168. doi: 10.1007/s10886005-6082-7

McElfresh, J. S., and Millar, J. G. (1999). Geographic variation in sex pheromone blend of Hemileuca electra from Southern California. J. Chem. Ecol. 25, 2505-2525. doi: 10.1023/A:1020826208715

McElfresh, J. S., and Millar, J. G. (2001). Geographic variation in the pheromone system of the saturniid moth Hemileuca eglanterina. Ecology 82, 3505-3518. doi: $10.2307 / 2680168$

Menegazzi, P., Yoshii, T., and Helfrich-Forster, C. (2012). Laboratory versus Nature: the two sides of the Drosophila circadian clock. J. Biol. Rhythms 27, 433-442. doi: $10.1177 / 0748730412463181$

Merlin, C., Beaver, L. E., Taylor, O. R., Wolfe, S. A., and Reppert, S. M. (2013). Efficient targeted mutagenesis in the monarch butterfly using zinc-finger nucleases. Genome Res. 23, 159-168. doi: 10.1101/gr.145599.112

Merlin, C., Gegear, R. J., and Reppert, S. M. (2009). Antennal circadian clocks coordinate sun compass orientation in migratory monarch butterflies. Science 325 , 1700-1704. doi: 10.1126/science.1176221 
Merlin, C., Lucas, P., Rochat, D., Francois, M. C., Maibeche-Coisne, M., and Jacquin-Joly, E. (2007). An antennal circadian clock and circadian rhythms in peripheral pheromone reception in the moth Spodoptera littoralis. J. Biol. Rhythms 22, 502-514. doi: 10.1177/0748730407307737

Miller, J. R., and Roelofs, W. L. (1980). Individual variation in sex pheromone component ratios in 2 populations of the redbanded leafroller moth, Argyrotaenia velutinana (Lepidoptera, Tortricidae). Environ. Entomol. 9, 359-363.

Miyasako, Y., Umezaki, Y., and Tomioka, K. (2007). Separate sets of cerebral clock neurons are responsible for light and temperature entrainment of Drosophila circadian locomotor rhythms. J. Biol. Rhythms 22, 115-126. doi: $10.1177 / 0748730407299344$

Miyatake, T. (2002). Circadian rhythm and time of mating in Bactrocera cucurbitae (Diptera: Tephritidae) selected for age at reproduction. Heredity 88, 302-306. doi: $10.1038 /$ sj.hdy.6800044

Miyatake, T., Matsumoto, A., Matsuyama, T., Ueda, H. R., Toyosato, T., and Tanimura, T. (2002). The period gene and allochronic reproductive isolation in Bactrocera cucurbitae. Proc. R. Soc. B-Biol. Sci. 269, 2467-2472. doi: 10.1098/rspb.2002.2152

Monti, L., Genermont, J., Malosse, C., and LalanneCassou, B. (1997). A genetic analysis of some components of reproductive isolation between two closely related species, Spodoptera latifascia (Walker) and S-descoinsi (LalanneCassou and Silvain) (Lepidoptera: Noctuidae). J. Evol. Biol. 10, 121-134. doi: $10.1007 / \mathrm{s} 000360050013$

Monti, L., Lalannecassou, B., Lucas, P., Malosse, C., and Silvain, J. F. (1995). Differences in sex pheromone communication systems of closely related species - Spodoptera latifascia (Walker) and S. descoinsi (Lalannecassou and Silvan) (Lepidoptera, Noctuidae). J. Chem. Ecol. 21, 641-660. doi: 10.1007/ BF02033707

Noguchi, H., and Tamaki, Y. (1985). Conspecific female sex pheromone delays calling behavior of Adoxophyes sp and Homon Magnanima (Lepidoptera, Tortricidae). Jpn. J. Appl. Entomol. Zool. 29, 113-118. doi: 10.1303/jjaez.29.113

Noldus, L., Potting, R. P. J., and Barendregt, H. E. (1991). Moth sex pheromone adsorption to leaf surface - bridge in time for chemical spies. Physiol. Entomol. 16, 329-344. doi: 10.1111/j.1365-3032.1991.tb00571.x

Ono, T., Charlton, R. E., and Carde, R. T. (1990). Variability in pheromone composition and periodicity of pheromone titer in potato tuberworm moth Phthorimaea operculella (Lepidoptera, Gelechiidae). J. Chem. Ecol. 16, 531-542. doi: 10.1007/BF01021784

Palanaswamy, P., and Seabrook, W. D. (1978). Behavioral responses of female eastern spruce budworm Choristoneura fumiferana (Lepidoptera, Tortricidae) to sex pheromone of her own species. J. Chem. Ecol. 4, 649-655. doi: 10.1007/BF00990275

Park, K. C., Cork, A., and Boom, K. S. (1996). Intrapopulational changes in sex pheromone composition during scotophase in oriental tobacco budworm, Helicoverpa assulta (Guenée) (Lepidoptera: Noctuidae). J. Chem. Ecol. 22, 1201-1210. doi: 10.1007/BF02027955

Pashley, D. P. (1986). Host-associated genetic differentiation in fall armyworm (Lepidoptera, Noctuidae) - a sibling species complex. Ann. Entomol. Soc. Am. 79, 898-904.

Pashley, D. P., Hammond, A. M., and Hardy, T. N. (1992). Reproductive isolating mechanisms in fall armyworm host strains (Lepidoptera, Noctuidae). Ann. Entomol. Soc. Am. 85, 400-405.

Peschel, N., and Helfrich-Forster, C. (2011). Setting the clock - by nature: circadian rhythm in the fruitfly Drosophila melanogaster. FEBS Lett. 585, 1435-1442. doi: 10.1016/j.febslet.2011.02.028

Peschel, N., Veleri, S., and Stanewsky, R. (2006). Veela defines a molecular link between Cryptochrome and Timeless in the light-input pathway to Drosophila's circadian clock. Proc. Natl. Acad. Sci. U.S.A. 103, 17313-17318. doi: 10.1073/pnas.0606675103

Petri, B., and Stengl, M. (1997). Pigment-dispersing hormone shifts the phase of the circadian pacemaker of the cockroach Leucophaea maderae. J. Neurosci. 17, 4087-4093.

Picimbon, J. F., Becard, J. M., Sreng, L., Clement, J. L., and Gadenne, C. (1995). Juvenile-hormone stimulates pheromonotropic brain factor release in the female black cutworm, Agrotis-Ipsilon. J. Insect Physiol. 41, 377-382. doi: 10.1016/0022-1910(94)00137-6

Plautz, J. D., Kaneko, M., Hall, J. C., and Kay, S. A. (1997). Independent photoreceptive circadian clocks throughout Drosophila. Science 278, 1632-1635. doi: $10.1126 /$ science. 278.5343 .1632
Pope, M. M., Gaston, L. K., and Baker, T. C. (1982). Composition, quantification and periodicity of sex pheromone gland volatiles from individual Heliothis virescens females. J. Chem. Ecol. 8, 1043-1055. doi: 10.1007/ BF00987885

Pope, M. M., Gaston, L. K., and Baker, T. C. (1984). Composition, quantification, and periodicity of sex pheromone volatiles from individual Heliothis zea females. J. Insect Physiol. 30, 943-945. doi: 10.1016/0022-1910(84) 90072-6

Prestwich, G. D., Vogt, R. G., and Riddiford, L. M. (1986). Binding and hydrolysis of radiolabeled pheromone and several analogs by male-specific antennal proteins of the moth Antheraea-polyphemus. J. Chem. Ecol. 12, 323-333. doi: 10.1007/BF01020559

Rafaeli, A. (1994). Pheromonotropic stimulation of moth pheromone gland cultures in-vitro. Arch. Insect Biochem. Physiol. 25, 287-299. doi: 10.1002/arch.9402 50405

Rafaeli, A., Bober, R., Becker, L., Choi, M. Y., Fuers, E. J., and Jurenka, R. (2007). Spatial distribution and differential expression of the PBAN receptor in tissues of adult Helicoverpa spp. (Lepidoptera: Noctuidae). Insect Mol. Biol. 16, 287-293. doi: 10.1111/j.1365-2583.2007.00725.x

Rafaeli, A., and Gileadi, C. (1995). Factors affecting pheromone production in the stored product moth, Plodia interpunctella - a preliminary study. J. Stored Prod. Res. 31, 243-247. doi: 10.1016/0022-474X(95)00008-U

Rafaeli, A., Gileadi, C., and Hirashima, A. (1999). Identification of novel synthetic octopamine receptor agonists which inhibit moth sex pheromone production. Pestic. Biochem. Physiol. 65, 194-204. doi: 10.1006/pest.1999.2446

Rafaeli, A., and Jurenka, R. (2003). "PBAN regulation of pheromone biosynthesis in female moths," in Pheromone Biochemistry and Molecular Biology, eds G. J. Blomquist and R. Vogt (London: Elsevier Academic Press), 107-136. doi: 10.1016/B978-012107151-6/50007-4

Rafaeli, A., and Klein, Z. (1994). Regulation of pheromone production by female pink bollworm moths Pectinophora gossypiella (Sanders) (Lepidoptera, Gelechiidae). Physiol. Entomol. 19, 159-164. doi: 10.1111/j.1365-3032.1994. tb01089.x

Rafaeli, A., and Soroker, V. (1989). Influence of diel rhythm and brain hormone on pheromone production in 2 lepidopteran species. J. Chem. Ecol. 15, 447-455. doi: 10.1007/BF01014691

Raina, A. K. (1993). Neuroendocrine control of sex pheromone biosynthesis in Lepidoptera. Annu. Rev. Entomol. 38, 329-349. doi: 10.1146/annurev.en.38. 010193.001553

Raina, A. K., Jaffe, H., Kempe, T. G., Keim, P., Blacher, R. W., Fales, H. M., et al. (1989). Identification of a neuropeptide hormone that regulates sex pheromone production in female moths. Science 244, 796-798. doi: 10.1126/science.244.4906.796

Raina, A. K., Klun, J. A., and Stadelbacher, E. A. (1986). Diel periodicity and effect of age and mating on female sex-pheromone titer in Heliothis-zea (Lepidoptera, Noctuidae). Ann. Entomol. Soc. Am. 79, 128-131.

Raina, A. K., and Stadelbacher, E. A. (1990). Pheromone titer and calling in Heliothis-virescens (Lepidoptera, Noctuidae) - effect of mating with normal and sterile backcross males. Ann. Entomol. Soc. Am. 83, 987-990.

Ramaswamy, S. B., Jurenka, R. A., Linn, C. E., and Roelofs, W. L. (1995). Evidence for the presence of a pheromonotropic factor in hemolymph and regulation of sex pheromone production in Helicoverpa zea. J. Insect Physiol. 41, 501-508. doi: 10.1016/0022-1910(94)00131-Y

Ramaswamy, S. B., Qiu, Y., and Park, Y. I. (1996). Neuronal control of postcoital pheromone production in the moth Heliothis virescens. J. Exp. Zool. 274, 255-263.

Raulston, J. R., Snow, J. W., Graham, H. M., and Lingren, P. D. (1975). Tobacco budworm: effect of prior mating and sperm content on the mating behavior of females. Ann. Entomol. Soc. Am. 68, 701-704.

Reppert, S. M., Gegear, R. J., and Merlin, C. (2010). Navigational mechanisms of migrating monarch butterflies. Trends Neurosci. 33, 399-406. doi: 10.1016/j.tins.2010.04.004

Reppert, S. M., Tsai, T., Roca, A. L., and Sauman, I. (1994). Cloning of a structural and functional homolog of the circadian clock gene period from the giant silkmoth Antheraea pernyi. Neuron 13, 1167-1176. doi: 10.1016/08966273(94)90054-X

Riemann, J. G., and Giebultowicz, J. M. (1991). Secretion in the upper vas deferens of the gypsy moth correlated with the circadian rhythm of sperm release from the testes. J. Insect Physiol. 37, 53-62. doi: 10.1016/0022-1910(91)90019-V 
Ritchie, M. G., and Kyriacou, C. P. (1994). Reproductive isolation and the period gene of Drosophila. Mol. Ecol. 3, 595-599. doi: 10.1111/j.1365294X.1994.tb00090.x

Roelofs, W. L., and Carde, R. T. (1971). Hydrocarbon sex pheromone in tiger moths (Arctiidae). Science 171, 684-686. doi: 10.1126/science.171.3972.684

Roelofs, W. L., and Cardé, R. T. (1974). "Sex pheromones in the reproductive isolation of lepidopterous species," in Pheromones, ed M. C. Birch (Amsterdam: North Holland Publishing), 96-114

Roelofs, W. L., Hill, A. S., Cardé, R. T., and Baker, T. C. (1974). 2 Sex pheromone components of tobacco budworm moth, Heliothis virescens. Life Sci. 14, 1555-1562. doi: 10.1016/0024-3205(74)90166-0

Rosen, W. Q., Han, G. B., and Lofstedt, C. (2003). The circadian rhythm of the sex-pheromone-mediated behavioral response in the turnip moth, Agrotis segetum, is not controlled at the peripheral level. J. Biol. Rhythms 18, 402-408. doi: $10.1177 / 0748730403256869$

Royer, L., and McNeil, J. N. (1993). Effect of relative-humidity conditions on responsiveness of European corn-borer (Ostrinia-nubilalis) males to female sex-pheromone in a wind-tunnel. J. Chem. Ecol. 19, 61-69. doi: 10.1007/BF00987471

Rund, S. S. C., Lee, S. J., Bush, B. R., and Duffield, G. E. (2012). Strainand sex-specific differences in daily flight activity and the circadian clock of Anopheles gambiae mosquitoes. J. Insect Physiol. 58, 1609-1619. doi: 10.1016/j.jinsphys.2012.09.016

Saario, C. A., Shorey, H. H., and Gaston, L. K. (1970). Sex pheromones of noctuid moths. XIX. Effect of environmental and seasonal factors on captures of males of Trichoplusia ni in pheromone-baited traps. Ann. Entomol. Soc. Am. 63, $667-672$.

Sadek, M. M., von Wowern, G., Lofstedt, C., Rosen, W. Q., and Anderson, P. (2012). Modulation of the temporal pattern of calling behavior of female Spodoptera littoralis by exposure to sex pheromone. J. Insect Physiol. 58, 61-66. doi: 10.1016/j.jinsphys.2011.09.016

Saito, O. (2000). Flight activity of three Spodoptera spp., Spodoptera litura, S. exigua and $S$. depravata, measured by flight actograph. Physiol. Entomol. 25, 112-119. doi: 10.1046/j.1365-3032.2000.00172.x

Sakai, T., and Ishida, N. (2001). Circadian rhythms of female mating activity governed by clock genes in Drosophila. Proc. Natl. Acad. Sci. U.S.A. 98, 9221-9225. doi: $10.1073 /$ pnas. 151443298

Sandrelli, F., Costa, R., Kyriacou, C. P., and Rosato, E. (2008). Comparative analysis of circadian clock genes in insects. Insect Mol. Biol. 17, 447-463. doi 10.1111/j.1365-2583.2008.00832.x

Santos, H., Paiva, M. R., Tavares, C., Kerdelhue, C., and Branco, M. (2011). Temperature niche shift observed in a Lepidoptera population under allochronic divergence. J. Evol. Biol. 24, 1897-1905. doi: 10.1111/j.14209101.2011.02318.x

Santos, H., Rousselet, J., Magnoux, E., Paiva, M. R., Branco, M., and Kerdelhue, C. (2007). Genetic isolation through time: allochronic differentiation of a phenologically atypical population of the pine processionary moth. Proc. R. Soc. B-Biol. Sci. 274, 935-941. doi: 10.1098/rspb.2006.3767

Sauman, I., Briscoe, A. D., Zhu, H. S., Shi, D. D., Froy, O., Stalleicken, J., et al. (2005). Connecting the navigational clock to sun compass input in monarch butterfly brain. Neuron 46, 457-467. doi: 10.1016/j.neuron.2005.03.014

Sauman, I., and Reppert, S. M. (1996). Circadian clock neurons in the silkmoth Antheraea pernyi: novel mechanisms of period protein regulation. Neuron 17 , 889-900. doi: 10.1016/S0896-6273(00)80220-2

Sauman, I., and Reppert, S. M. (1998). Brain control of embryonic circadian rhythms in the silkmoth Antheraea pernyi. Neuron 20, 741-748. doi: 10.1016/S0896-6273(00)81012-0

Sauman, I., Tsai, T., Roca, A. L., and Reppert, S. M. (2000). Period protein is necessary for circadian control of egg hatching behavior in the silkmoth Antheraea pernyi (vol 17, pg 901, 1996). Neuron 27, U12-U12. doi: 10.1016/S08966273(02)02716-2

Schal, C., and Carde, R. T. (1986). Effects of temperature and light on calling in the tiger moth Holomelina lamae (Freeman) (Lepidoptera, Arctiidae). Physiol. Entomol. 11, 75-87. doi: 10.1111/j.1365-3032.1986.tb00392.x

Schal, C., Charlton, R. E., and Cardé, R. T. (1987). Temporal patterns of sex pheromone titers and release rates in Holomelina lamae (Lepidoptera, Arctiidae). J. Chem. Ecol. 13, 1115-1129. doi: 10.1007/BF01020542

Schal, C., Holbrook, G. L., Bachmann, J. A. S., and Sevala, V. L. (1997) Reproductive biology of the German cockroach, Blattella germanica: Juvenile hormone as a pleiotropic master regulator. Arch. Insect Biochem. Physiol. 35, 405-426.

Schneider, N. L., and Stengl, M. (2005). Pigment-dispersing factor and GABA synchronize cells of the isolated circadian clock of the cockroach Leucophaea maderae. J. Neurosci. 25, 5138-5147. doi: 10.1523/JNEUROSCI.5138-A04.2005

Schöfl, G., Heckel, D. G., and Groot, A. T. (2009). Time-shifted reproductive behaviours among fall armyworm (Noctuidae: Spodoptera frugiperda) host strains: evidence for differing modes of inheritance. J. Evol. Biol. 22, 1447-1459. doi: 10.1111/j.1420-9101.2009.01759.x

Schuckel, J., Siwicki, K. K., and Stengl, M. (2007). Putative circadian pacemaker cells in the antenna of the hawkmoth Manduca sexta. Cell Tissue Res. 330, 271-278. doi: 10.1007/s00441-007-0471-x

Sehadova, H., Glaser, F. T., Gentile, C., Simoni, A., Giesecke, A., Albert, J. T., et al. (2009). Temperature entrainment of Drosophila's circadian clock involves the gene nocte and signaling from peripheral sensory tissues to the brain. Neuron 64, 251-266. doi: 10.1016/j.neuron.2009.08.026

Sehadova, H., Markova, E. P., Sehnal, F. S., and Takeda, M. (2004). Distribution of circadian clock-related proteins in the cephalic nervous system of the silkworm, Bombyx mori. J. Biol. Rhythms 19, 466-482. doi: 10.1177/0748730404269153

Seybold, S. J., and Tittiger, C. (2003). Biochemistry and molecular biology of De Novo Isoprenoid pheromone production in the Scolytidae. Annu. Rev. Entomol. 48, 425-453. doi: 10.1146/annurev.ento.48.091801.112645

Shafer, O. T., Kim, D. J., Dunbar-Yaffe, R., Nikolaev, V. O., Lohse, M. J., and Taghert, P. H. (2008). Widespread receptivity to neuropeptide PDF throughout the neuronal circadian clock network of Drosophila revealed by real-time cyclic AMP imaging. Neuron 58, 223-237. doi: 10.1016/j.neuron.2008.02.018

Shorey, H. H., McFarlan, S. U., and Gaston, L. K., (1968). Sex pheromones of noctuid moths. 13. Changes in pheromone quantity as related to reproductive age and mating history in females of 7 species of Noctuidae (Lepidoptera). Ann. Entomol. Soc. Am. 61, 372-376.

Silvegren, G., Lofstedt, C., and Rosen, W. Q. (2005). Circadian mating activity and effect of pheromone pre-exposure on pheromone response rhythms in the moth Spodoptera littoralis. J. Insect Physiol. 51, 277-286. doi: 10.1016/j.jinsphys.2004.11.013

Skals, N., Anderson, P., Kanneworff, M., Lofstedt, C., and Surlykke, A. (2005). Her odours make him deaf: crossmodal modulation of olfaction and hearing in a male moth. J. Exp. Biol. 208, 595-601. doi: 10.1242/jeb.01400

Smith, P. H. (1979). Genetic manipulation of the circadian clocks timing of sexual behavior in the Queensland fruit flies, Dacus tryoni and Dacus neohumeralis. Physiol. Entomol. 4, 71-78. doi: 10.1111/j.1365-3032.1979.tb00179.x

Sower, L. L., Shorey, H. H., and Gaston, L. K. (1971). Sex pheromones of noctuid moths. 25. Effects of temperature and photoperiod on circadian rhythms of sex pheromone release by females of Trichoplusia ni (Lepidoptera, Noctuidae). Ann. Entomol. Soc. Am. 64, 488-492.

Spurgeon, D. W., Lingren, P. D., Raulston, J. R., and Shaver, T. N. (1995). Agespecific mating activities of Mexican rice borers (Lepidoptera, Pyralidae). Environ. Entomol. 24, 105-109.

Stelinski, L. L., Il'Ichev, A. L., and Gut, L. J. (2006). Antennal and behaviora responses of virgin and mated oriental fruit moth (Lepidoptera: Tortricidae) females to their sex pheromone. Ann. Entomol. Soc. Am. 99, 898-904. doi: 10.1603/0013-8746(2006)99[898:AABROV]2.0.CO;2

Tang, J. D., Charlton, R. E., Jurenka, R. A., Wolf, W. A., Phelan, P. L., Sreng, L., et al. (1989). Regulation of pheromone biosynthesis by a brain hormone in 2 moth species. Proc. Natl. Acad. Sci. U.S.A. 86, 1806-1810. doi: 10.1073/pnas.86. 6.1806

Tauber, E., and Kyriacou, C. P. (2005). "Molecular evolution and population genetics of circadian clock genes," in Circadian Rhythms, ed M. W. Young (San Diego, CA: Elsevier Academic Press Inc.), 797-817. doi: 10.1016/S00766879(05)93042-5

Tauber, E., Roe, H., Costa, R., Hennessy, J. M., and Kyriacou, C. P. (2003). Temporal mating isolation driven a behavioral gene in Drosophila. Curr. Biol. 13, 140-145. doi: 10.1016/S0960-9822(03)00004-6

Teal, P. E. A., Byers, J. R., and Philogene, B. J. R. (1978). Differences in female calling behavior of three interfertile sibling species of Euxoa (Lepidoptera, Noctuidae). Ann. Entomol. Soc. Am. 71, 630-634.

Truman, J. W. (1972). Involvement of a photoreversible process in circadian clock controlling silkmoth eclosion. Z. Vergl. Physiol. 76, 32-40. doi: 10.1007/BF00 395499 
Truman, J. W. (1974). Physiology of insect rhythms. 4. Role of brain in regulation of flight rhythm of giant silkmoths. J. Comp. Physiol. 95, 281-296. doi: 10.1007/BF00609702

Tsfadia, O., Azrielli, A., Falach, L., Zada, A., Roelofs, W., and Rafaeli, A. (2008). Pheromone biosynthetic pathways: PBAN-regulated rate-limiting steps and differential expression of desaturase genes in moth species. Insect Biochem. Mol. Biol. 38, 552-567. doi: 10.1016/j.ibmb.2008.01.005

Turgeon, J. J., and McNeil, J. N. (1983). Modifications in the calling behavior of Pseudaletia unipuncta (Lepidoptera, Noctuidae), induced by temperature conditions during pupal and adult development. Can. Entomol. 115, 1015-1022. doi: 10.4039/Ent1151015-8

Turgeon, J., and McNeil, J. (1982). Calling behavior of the armyworm, Pseudaletia unipuncta. Entomol. Exp. Appl. 31, 402-408. doi: 10.1111/j.15707458.1982.tb03168.x

Tychsen, P. H., and Fletcher, B. S. (1971). Studies on rhythm of mating in Queensland fruit fly, Dacus tryoni. J. Insect Physiol. 17, 2139-2156. doi: 10.1016/ 0022-1910(71)90174-0

Unbehend, M., Hanniger, S., Meagher, R. L., Heckel, D. G., and Groot, A. T. (2013). Pheromonal divergence between two strains of Spodoptera frugiperda. J. Chem. Ecol. 39, 364-376. doi: 10.1007/s10886-013-0263-6

Vanin, S., Bhutani, S., Montelli, S., Menegazzi, P., Green, E. W., Pegoraro, M., et al. (2012). Unexpected features of Drosophila circadian behavioural rhythms under natural conditions. Nature 484, 371-375. doi: 10.1038/ nature 10991

Webster, R. P., and Carde, R. T. (1984). The effects of mating, exogenous juvenile hormone and a juvenile hormone analog on pheromone titer, calling and oviposition i the omnivorous leafroller moth (Platynota stultana). J. Insect Physiol. 30, 113-118. doi: 10.1016/0022-1910(84)90114-8

Webster, R. P., and Cardé, R. T. (1982). Relationships among pheromone titer, calling and age in the omnivorous leafroller moth (Platynota stultana). J. Insect Physiol. 28, 925-933. doi: 10.1016/0022-1910(82)90108-1

Wei, H. Y., Huang, Y. P., and Du, J. W. (2004). Sex pheromones and reproductive behavior of Spodoptera litura (Fabricius) moths reared from larvae treated with four insecticides. J. Chem. Ecol. 30, 1457-1466. doi: 10.1023/B:JOEC.00000 37751.86203.10

West, R. J., Teal, P. E. A., Laing, J. E., and Grant, G. M. (1984). Calling behavior of the potato stem borer, Hydraecia micacea Esper (Lepidoptera, Noctuidae) in the laboratory and the field. Environ. Entomol. 13, 1399-1404.

Wise, S., Davis, N. T., Tyndale, E., Noveral, J., Folwell, M. G., Bedian, V., et al. (2002). Neuroanatomical studies of period gene expression in the hawkmoth, Manduca sexta. J. Comp. Neurol. 447, 366-380. doi: 10.1002/cne. 10242

Xiang, Y. Y., Yang, M. F., and Li, Z. Z. (2010). Calling behavior and rhythms of sex pheromone production in the black cutworm moth in china. J. Insect Behav. 23, 35-44. doi: 10.1007/s10905-009-9193-0

Xu, J., Huigens, M. E., Orr, D., and Groot, A. T. (in press). Differential response of Trichogramma wasps to extreme sex pheromone types of the noctuid moth Heliothis virescens. Ecol. Entomol.
Yoshii, T., Vanin, S., Costa, R., and Helfrich-Forster, C. (2009). Synergic entrainment of Drosophila's circadian clock by light and temperature. J. Biol. Rhythms 24, 452-464. doi: 10.1177/0748730409348551

Young, M. W., WagerSmith, K., Vosshall, L., Saez, L., and Myers, M. P. (1996). Molecular anatomy of a light-sensitive circadian pacemaker in Drosophila. Cold Spring Harb. Symp. Quant. Biol. 61, 279-284. doi: 10.1101/SQB.1996.061.01.030 Zavodska, R., Fexova, S., von Wowern, G., Han, G. B., Dolezel, D., and Sauman, I. (2012). Is the sex communication of two pyralid moths, Plodia interpunctella and Ephestia kuehniella, under circadian clock regulation? J. Biol. Rhythms 27, 206-216. doi: 10.1177/0748730412440689

Zavodska, R., Sauman, I., and Sehnal, F. (2003). Distribution of PER protein, pigment-dispersing hormone, prothoracicotropic hormone, and eclosion hormone in the cephalic nervous system of insects. J. Biol. Rhythms 18, 106-122. doi: 10.1177/0748730403251711

Zhan, S., Merlin, C., Boore, J. L., and Reppert, S. M. (2011). The Monarch butterfly genome yields insights into long-distance migration. Cell 147, 1171-1185. doi: 10.1016/j.cell.2011.09.052

Zhang, E. E., and Kay, S. A. (2010). Clocks not winding down: unravelling circadian networks. Nat. Rev. Mol. Cell Biol. 11, 764-776. doi: 10.1038/nrm2995

Zhu, H. S., Gegear, R. J., Casselman, A., Kanginakudru, S., and Reppert, S. M. (2009). Defining behavioral and molecular differences between summer and migratory monarch butterflies. BMC Biol. 7:14. doi: 10.1186/1741-7007-7-14

Zhu, H. S., Sauman, I., Yuan, Q., Casselman, A., Emery-Le, M., Emery, P., et al. (2008). Cryptochromes define a novel circadian clock mechanism in monarch butterflies that may underlie sun compass navigation. PLoS Biol. 6, 138-155. doi: 10.1371/journal.pbio.0060004

Zhu, H. S., Yuan, Q., Briscoe, A. D., Froy, O., Casselman, A., and Reppert, S. M. (2005). The two CRYs of the butterfly. Curr. Biol. 15, R953-R954. doi: 10.1016/j.cub.2005.11.030

Zhu, J. W., Chastain, B. B., Spohn, B. G., and Haynes, K. F. (1997). Assortative mating in two pheromone strains of the cabbage looper moth, Trichoplusia ni. J. Insect Behav. 10, 805-817. doi: 10.1023/B:JOIR.0000010414.28494.9a

Conflict of Interest Statement: The author declares that the research was conducted in the absence of any commercial or financial relationships that could be construed as a potential conflict of interest.

Received: 31 May 2014; accepted: 16 July 2014; published online: 07 August 2014.

Citation: Groot AT (2014) Circadian rhythms of sexual activities in moths: a review. Front. Ecol. Evol. 2:43. doi: 10.3389/fevo.2014.00043

This article was submitted to Chemical Ecology, a section of the journal Frontiers in Ecology and Evolution.

Copyright (C) 2014 Groot. This is an open-access article distributed under the terms of the Creative Commons Attribution License (CC BY). The use, distribution or reproduction in other forums is permitted, provided the original author(s) or licensor are credited and that the original publication in this journal is cited, in accordance with accepted academic practice. No use, distribution or reproduction is permitted which does not comply with these terms. 